\title{
Fast Auroral Evolution and Related Magnetic Field Changes on the Ground and at Conjugate Satellites
}

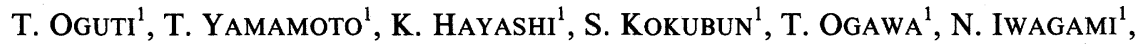

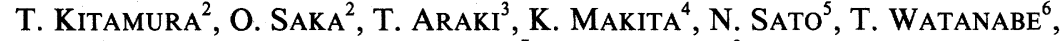 \\ R. E. HORITA ${ }^{7}$, and J. S. KIM ${ }^{8}$ \\ ${ }^{1}$ Geophysics Research Laboratory, University of Tokyo, Tokyo 113, Japan \\ ${ }^{2}$ Department of Physics, Kyushu University, Fukuoka 812, Japan \\ ${ }^{3}$ Data Analysis Center for Geomagnetism and Spacemagnetism, Kyoto University, Kyoto 606, Japan \\ ${ }^{4}$ Department of Engineering, Takushoku University, Tokyo 112, Japan \\ ${ }^{5}$ National Institute of Polar Research, Tokyo 173, Japan \\ ${ }^{6}$ Department of Geophysics and Astronomy, University of British Columbia, \\ Vancouver, B.C. V6T 1W5, Canada \\ ${ }^{7}$ Department of Physics and Astronomy, University of Victoria, Victoria, B.C. V8W 2Y2, Canada \\ ${ }^{8}$ Department of Atmospheric Sciences, State University of New York, Albany, NY 12222, U.S.A.
}

(Received October 5, 1987; Revised January 19, 1988)

Auroral activities on January 7, 1986, are examined with all-sky video data obtained at multiple stations. It is shown that a poleward expansion front of an expansion aurora usually consists of many northwestward protrusions which develop and decay here and there during the course of the auroral expansion. Developments of characteristic auroral protrusions are compared with magnetic field changes on the ground. The result shows that the developments of large magnetic field deflections on the ground are most likely due to enhancements of local westward electrojets associated with counterclockwise vortex currents around developing auroral protrusions in the night sector. The developments of auroral protrusions are also related to magnetic field changes at the synchronous satellites, GOES 5 and 6 , conjugate with the auroral forms. Characteristic changes of magnetic field occur at GOES 5 and 6 concurrently with developments of auroral protrusions around respective magnetic footpoints of the satellites. Auroral structures within or in the vicinity of auroral protrusions are likely interlinked with the field-aligned currents around the conjugate synchronous satellites.

\section{Introduction}

Relationship between auroral and magnetic variations in the auroral zone has long been one of the most important subjects in the study of magnetospheric substorms and substorm-related electric currents in the ionosphere-magnetosphere system. For example, KAMIDE and AKASOFU (1975) examined auroral images from DMSP satellite along with ground magnetic variations, and showed that a strong westward electrojet was often located around the poleward edge of the auroral bulge. A breakup aurora was studied with radar measurements of ionospheric drifts and 
ground magnetic field changes, and strong field-aligned currents were suggested at the western part of an active auroral region (e.g., BAUMJOHANN et al., 1981). Fieldaligned currents measured by low altitude satellite were also related to auroral distributions (e.g., KAMIDE and AKASOFU, 1976; KAMIDE and ROSTOKER, 1977).

As for the relationship between electric fields and electric currents, many studies have been carried out looking for the mutually consistent electric fields, electric currents, involving the field-aligned currents, and conductivity distributions. For example, YASUHARA et al. (1982) and CAUDAL (1987) showed that field-aligned currents estimated from observation of electric fields and a model distribution of ionospheric conductivity are roughly consistent with those observationally obtained by IIJIMA and POTEMRA $(1976,1978)$.

Many of these kinds of studies are based upon meridian observations. Meridian scanning radar observations (e.g., YASUHARA et al., 1982; CAUDAL, 1987), and meridian chains of magnetic stations (e.g., KAMIDE and RICHMOND, 1982) are often used to infer the two-dimensional distribution of the electric fields and the electric currents, respectively. This treatment crucially requires temporal stationarity to a high degree. In fact, however, such a high degree of stationarity is rarely achieved as pointed out by CAUDAL (1987). Moreover, the insufficient information such as of the conductivity distribution and the electric fields has forced many people to assume a "model" distribution of conductivity and sometimes "model" electric fields in estimating the current system. Thus, the result inevitably depends on the model. The model, or even the "average" distribution leads to an inconsistent conclusion unless the model or average of conductivity, electric fields and field-aligned currents are all consistent with one another. This means that we need the two-dimensional data set in the same time interval for obtaining consistent results. In a recent computation, KAMIDE et al. (1986) used the ionospheric conductivity distribution, estimated with auroral images observed by DE satellite, and simultaneous magnetic field variations on the ground.

In addition, both the ionospheric electric field and the conductivity rapidly change both in space and time during the course of an auroral substorm. The rapid spatio-temporal changes in conductivity can be expected from the changes of ionization rate as inferred from the rapid changes in auroral luminosity distribution (OGUTI and HAYASHI, 1984). The fast variations in the electric fields are inferred from the fast changes in the auroral drifts (NAKAMURA and OGUTI, 1987). From auroral observation, it is evident that the distribution of the ionospheric conductivity (or luminosity) and that of the electric fields (or drifts) vary having an essential mutual relation to each other both in space and time. This mutually related spatiotemporal variation must be taken into consideration in any consistent estimation of the electric currents.

In space, the magnetic field shows characteristic changes during the time of a substorm (e.g., FAIRFIELD, 1973; KOKUBUN and MCPHERRON, 1981; NAGAI, 1982, 1987; BARFIELD et al., 1985). The magnetic field variations are usually understood in terms of local disruption of the cross-tail current associated with the formation of a current wedge (MCPHERRON et al., 1973). As NAGAI (1982) shows, the gross feature 
of the magnetic field changes at synchronous satellites appears to support this idea. However, the field-aligned current cannot be a line current in the iono-magnetospheric plasma because any field-aligned current should be accompanied by return currents from the ionosphere in keeping the mutual consistency among the electric fields, conductivity distributions and currents. The field-aligned currents could locally close and, consequently, not produce significant magnetic fields beyond a certain distance as suggested by NISHITANI and OGUTI (1988).

During the Global Aurora Dynamics Campaign which was carried out during the period from December 20, 1985, to February 3, 1986 (OGUTI et al., 1988), an all-sky auroral TV camera network was operated in the Canada-Alaska area along the northern auroral zone. The purpose of this paper is 1) to study large-scale auroral evolutions with TV records of auroras, 2) to compare the auroral evolutions with magnetic field variations both on the ground and satellites, and 3) to examine the current structures in the iono-magnetospheric system which could be linked to the auroras. This study is the first step to estimate the mutually consistent electric fields, electric currents, conductivity distributions and magnetic fields, all varying both in space and time.

\section{Data}

The auroral data used in this study were obtained by all-sky TV cameras at Fort Smith $\left(60.0^{\circ}, 248.1^{\circ}\right.$, geographic coordinates; $68.2^{\circ}, 299.5^{\circ}$, geomagnetic coordinates), La Ronge $\left(55.2^{\circ}, 254.7^{\circ} ; 64.9^{\circ}, 310.8^{\circ}\right)$, Shamattawa $\left(55.9^{\circ}, 267.9^{\circ}\right.$; $\left.67.8^{\circ}, 330.1^{\circ}\right)$, Little Grand Rapids $\left(52.0^{\circ}, 264.5^{\circ} ; 63.5^{\circ}, 325.8^{\circ}\right)$ and Great Whale River $\left(55.3^{\circ}, 282.2^{\circ} ; 68.0^{\circ}, 353.7^{\circ}\right)$, Canada, from 02:00 to 09:00 UT on January 7 , 1986. The TV data from Ny Ålesund $\left(78.9^{\circ}, 11.9^{\circ} ; 75.9^{\circ}, 114.7^{\circ}\right)$, Spitzbergen, Poker Flat $\left(65.1^{\circ}, 212.5^{\circ} ; 65.1^{\circ}, 259.7^{\circ}\right)$, Alaska, and from Husafell $\left(64.7^{\circ}, 339.1^{\circ} ; 67.2^{\circ}\right.$, $70.7^{\circ}$ ), Iceland, are also referred to. Most of the ground magnetic data are from standard magnetic observatories in the Canada-Greenland area as well as from our temporal campaign stations. The observation system and its specifications are briefly described by OGUTI et al. (1988). The magnetic field data from GOES $5\left(74.6^{\circ} \mathrm{W}\right)$ and GOES $6\left(108.0^{\circ} \mathrm{W}\right)$ synchronous satellites are also used. These satellites are located in the conjugate region with the auroral observation area of the campaign.

In this study we examine five examples of auroral activities during the following time intervals; 02:30-03:00 UT, 05:30-06:00 UT, 06:30-07:00 UT, 07:00-07:40 UT and 07:50-08:20 UT on January 7, 1986. Large-scale auroral evolutions are compared with the magnetic field variations both on the ground and at GOES 5 and 6 satellites for these time intervals.

\section{General Activities of Aurora}

Auroral activities are first examined by means of meridian displays. Figures 1 through 5 show meridian displays of auroras observed at multiple stations for the five time intervals. In each row (station) in each figure, the abscissa is time in UT and the 


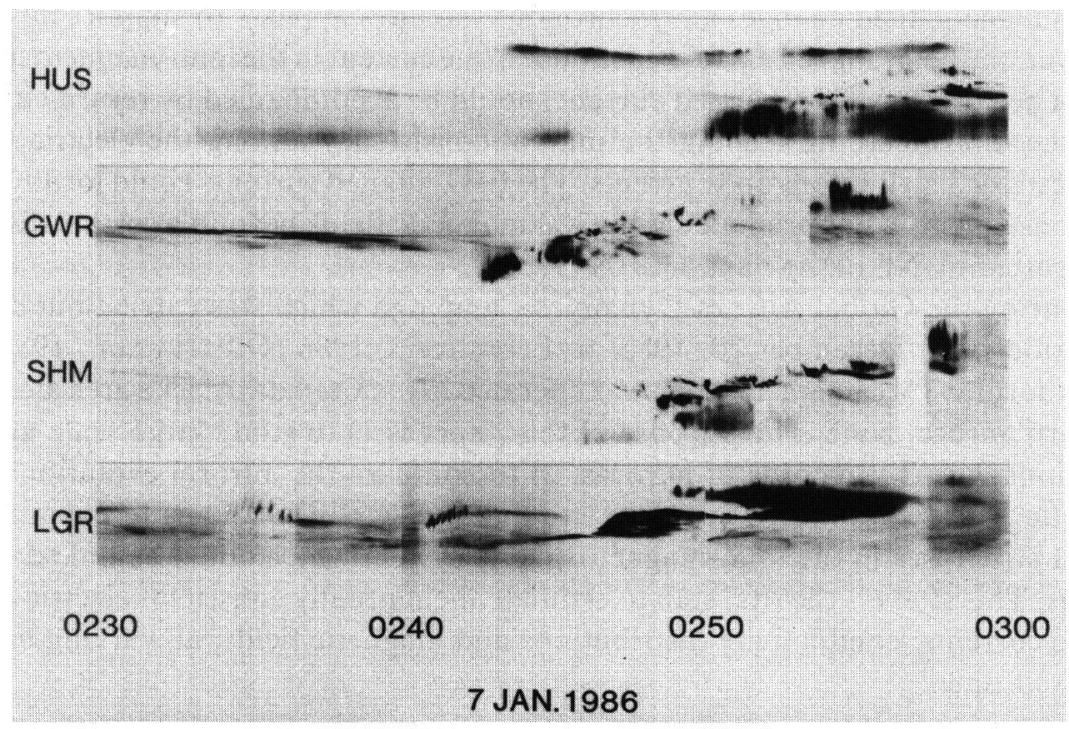

Fig. 1. Meridian display of example A aurora, from 02:30 to 03:00 UT on January 7, 1986. The ordinate indicates the distance along the meridian line in linear scale at the auroral altitude, and the abscissa is time in UT. The upper and the lower boundary of each row are $300 \mathrm{~km}$ north and south from each station, respectively. The image is negative. The darkness represents the auroral luminosity.

ordinate represents distance along the meridian line. The upper and the lower boundaries of each row are $300 \mathrm{~km}$ north and south from each station, respectively. The ordinate scale is linear. The location of auroras is converted from the all-sky frame to the linear scale on an assumption of $100 \mathrm{~km}$ altitude. The image is negative so that the darkness represents the auroral luminosity.

\subsection{Example A (02:38 UT)}

The meridian displays of auroras in Fig. 1 show that an auroral expansion started around 02:42 above Great Whale River. As seen later, the true onset time of this expansion was about $02: 38$, or a little earlier. At that time, most of the campaign stations, except Husafell, were located in the dusk sector (Fig. 1). Husafell was in the early morning. As seen in the figure, the poleward expansion of the aurora began at 02:42 above Great Whale River, while it started at 02:46 above Little Grand Rapids, at 02:49 above Shamattawa and at 02:50 at Husafell. The time sequence appears to be reasonable because the substorm expansion of aurora usually begins around magnetic midnight and expands both eastward and westward as it expands poleward. An important point is that the expansion shows quite intricate structures on the position-time display, suggesting that the expansion develops locally here and there.

Note that the distance along the meridian (ordinate) is given by a linear scale. If 


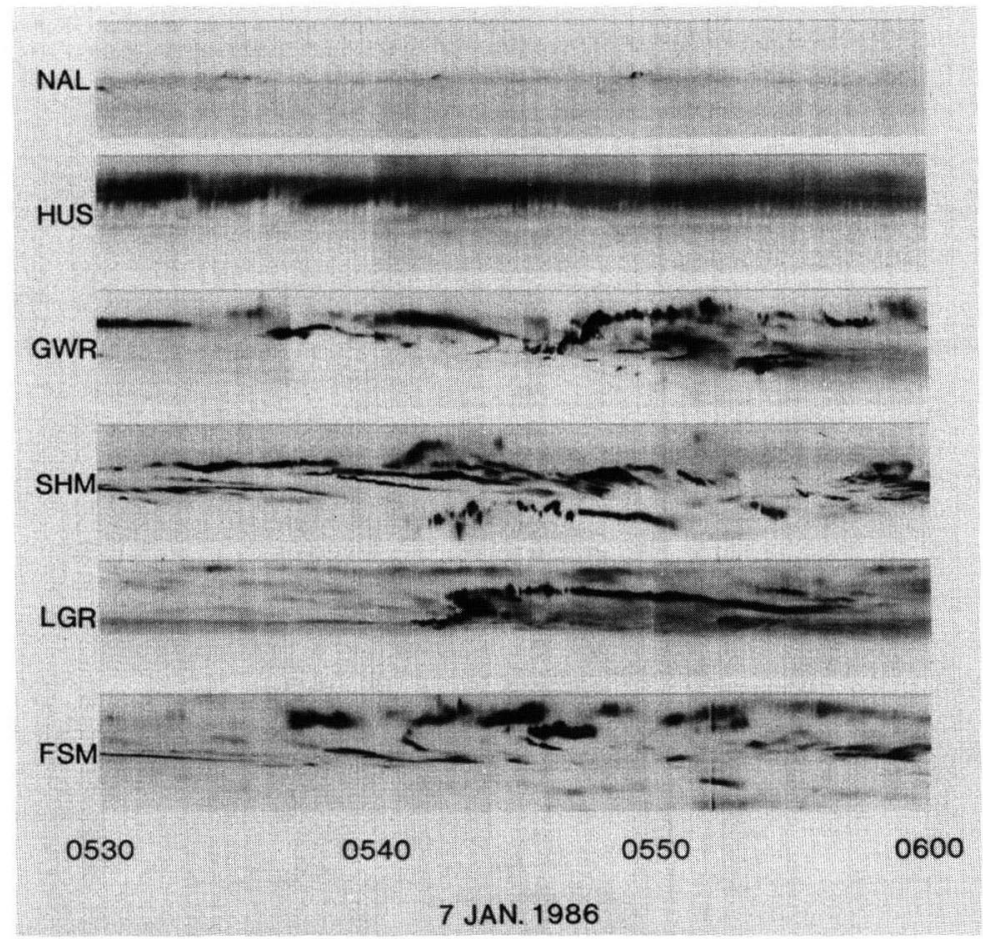

Fig. 2. Meridian display of example B aurora, from 05:30 to 06:00 UT on January 7, 1986. The format is the same as Fig. 1.

the ordinate is given by an elevation angle, the pattern of the poleward expansion would be quite different from, usually much simpler in form than, that in this figure. The intricate structures of the poleward expansion front in this figure are partly due to the linear scale expression of the auroral location.

\subsection{Example $B(05: 40$ UT)}

Figure 2 shows meridian displays of an auroral expansion which broke out at 05:40 UT above Fort Smith and Little Grand Rapids. Here, Fort Smith, Little Grand Rapids and Shamattawa were in the dusk sectors and Great Whale River and Husafell were in the dawn. Ny Ålesund was located about 3 hours before magnetic noon. The auroral structure of this example was very complex. There were so many auroral arcs. The expansion was well-defined only above Little Grand Rapids and Fort Smith at 05:41 UT. The expansion front did not reach the multiple arcs above Shamattawa. The arcs above Shamattawa remained unchanged while the expansion was going on above Little Grand Rapids. Another expansion occurred above Great Whale River at 05:46. Concurrent brightenings of auroras could be pointed out between the dayside 


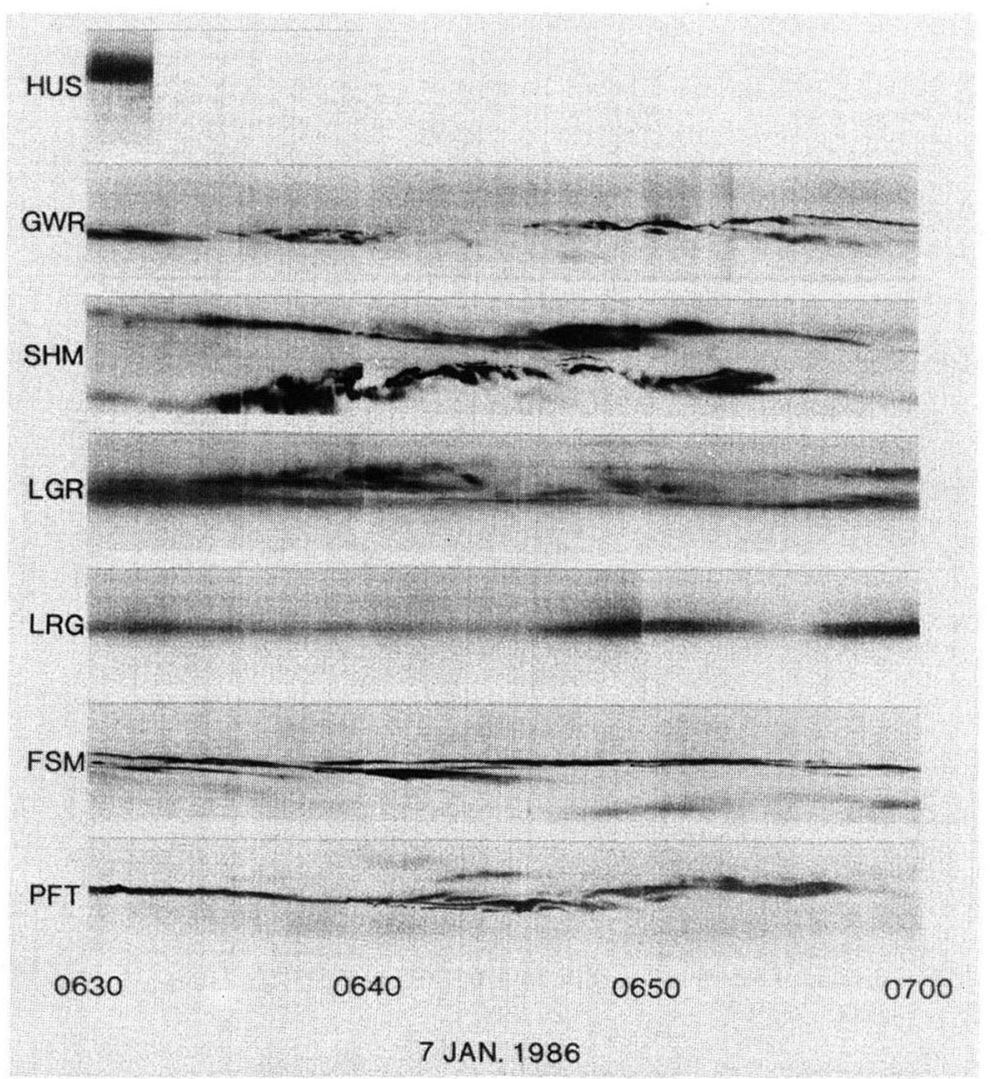

Fig. 3. Meridian display of example C aurora, from 06:30 to 07:00 UT on January 7, 1986. The format is the same as Fig. 1.

auroras at 05:35, 05:42 and 05:50 above Ny Alesund and those at night in the northernmost sky as seen from Great Whale River at 05:36 and from Shamattawa at 05:44 and 05:52. Apart from the expansion, quasi-periodic poleward propagations of pulsating auroras with period of about 4 minutes were seen from 05:30 to 05:45 above Husafell located in the dawn sector. These long-period auroral pulsations are discussed by YAMAMOTO et al. $(1987 \mathrm{a}, \mathrm{b})$ in connection with concurrent magnetic pulsations.

\subsection{Example $C(06: 35$ UT)}

Figure 3 shows similar meridian displays of example $\mathrm{C}$ aurora. Little Grand Rapids and Shamattawa were located at the magnetic midnight at that time. This expansion was small. Still, it showed a typical evolution. The expansion began above Little Grand Rapids at 06:35 UT, then expanded poleward above Shamattawa. At the 


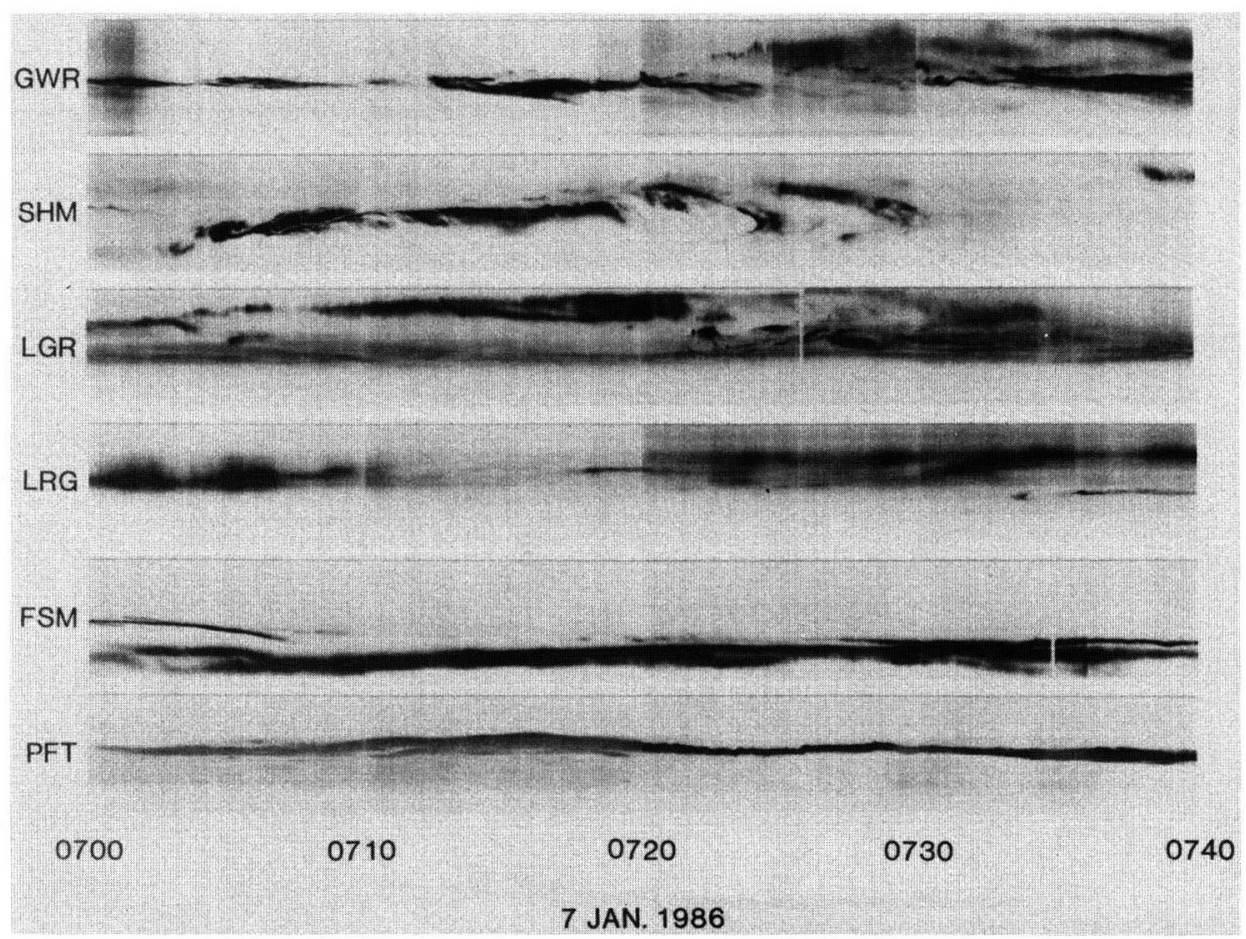

Fig. 4. Meridian display of example D aurora, from 07:00 to 07:40 UT on January 7, 1986. The format is the same as Fig. 1.

same time it expanded both eastward and westward, successively covering Great Whale River at 06:37, Fort Smith at 06:38 and Poker Flat at 06:41. At these three stations, the expansion revealed itself just a small splitting of auroral arcs. The expansion aurora must have covered La Ronge, where it was overcast unfortunately. As seen at Shamattawa, a stable auroral arc located a little poleward of the expansion aurora was enhanced in luminosity at the expansion onset at 06:35. However, the stable arc did not show any tendency of the poleward expansion at that time. The poleward expansion of this arc began when the southern expansion aurora approached it at 06:47.

\subsection{Example D (07:04 UT)}

The aurora in Fig. 4 shows again a complicated expansion started at 07:04 UT. La Ronge was located at the magnetic midnight, still a little overcast. Fort Smith and Poker Flat were in the dusk and rest of the stations were in the dawn. The expansion started above Shamattawa and Little Grand Rapids at 07:04. The slow poleward expansion lasted about 16 minutes and then the second larger expansion took place 


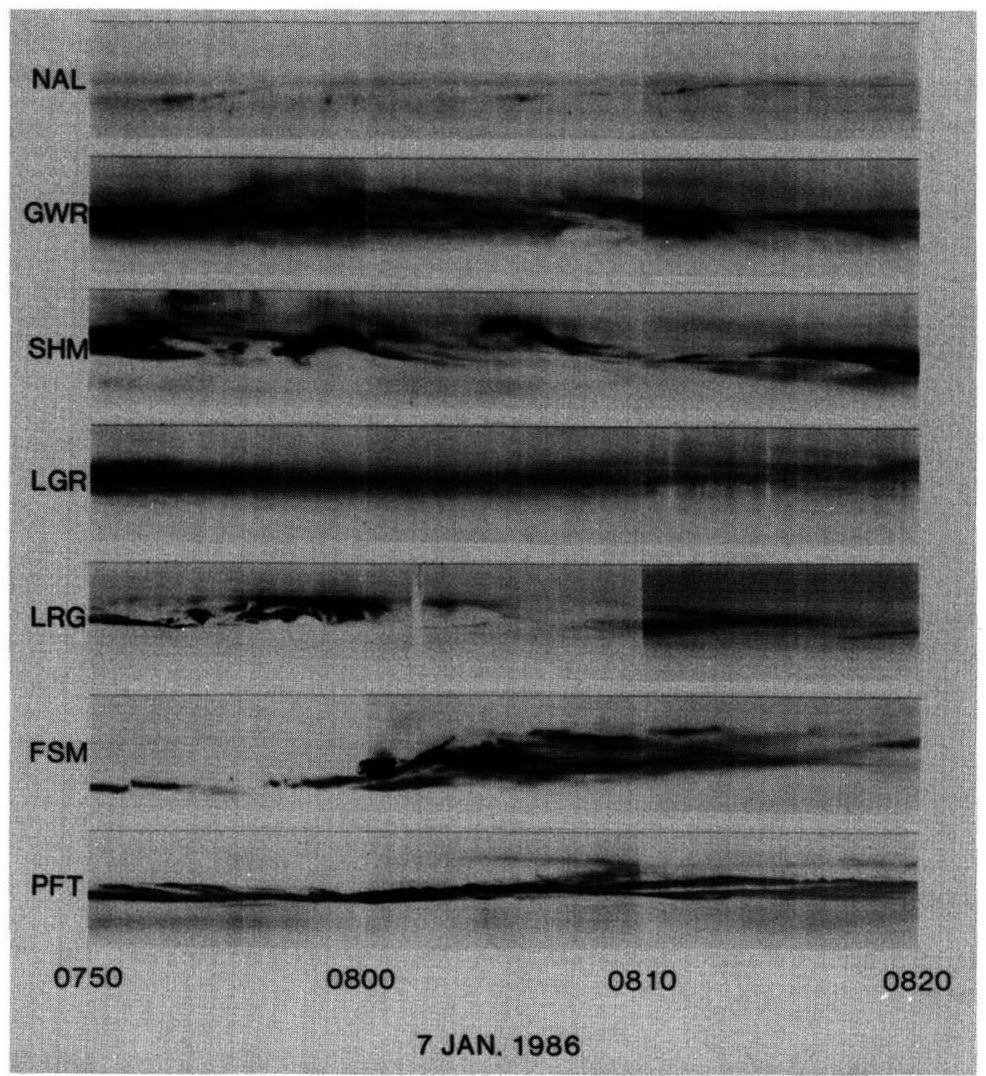

Fig. 5. Meridian display of example E aurora, from 07:50 to 08:20 UT on January 7, 1986. The format is the same as Fig. 1.

above Great Whale River and Shamattawa at 07:20. No clear tendency of expansion was seen at La Ronge, Fort Smith and Poker Flat at that time.

\subsection{Example E (08:00 UT)}

The magnetic midnight meridian here was located in between La Ronge and Fort Smith. The auroral expansion at 08:00 UT occurred only above Fort Smith as seen in Fig. 5. No clear tendency of expansion was seen above Shamattawa. This was preceded by another small expansion at 07:55 above La Ronge. Enhancements in auroral luminosity at the dayside cusp, Ny Ålesund, occurred concurrently with those in the northern sky of Shamattawa, e.g., at 07:53, 07:59, 08:06 and 08:11, in this example again. The region of pulsating aurora extended above Little Grand Rapids, and in the southern sky of Great Whale River from 08:05 to 08:20 although not clear in this figure. 
As seen in these figures, the poleward expansion front of aurora usually is highly structured. However, the intricacy of the poleward expansion front is not clearly seen unless auroras are plotted in linear scale.

\section{Large Scale Evolution of Auroral Pattern}

All-sky images of auroras are mapped onto the ionospheric coordinates with a TV image processor assuming $100 \mathrm{~km}$ altitude. The converted images from multiple stations are combined together to study large scale auroral deformations.

As mentioned in the previous section, an auroral expansion front is highly structured. This is mostly due to the fact that the vortex-chain aurora (OGUTI, 1981; curtain-like or discrete aurora) is usually characterized by developments of polewardwestward and equatorward-eastward protrusions having various scale sizes (OGUTI, 1975). These protrusions are often called "westward traveling surge" while sometimes they do not travel at all. The protrusions, then, rotate clockwise viewed in the magnetic field direction, and are eventually reformed into straight arcs again.

\subsection{Example $A$}

The sequential pictures in Fig. 6 show large scale auroral deformations of the example A aurora above Great Whale River, Shamattawa and Little Grand Rapids. The TV cameras at other stations in Canada were not in operation. Two independent auroral protrusions developed northwestward above Little Grand Rapids and Great Whale River at 02:45, as indicated by arrows in the figure. As the first protrusion above Little Grand Rapids extended westward with decrease in luminosity, another protrusion developed above Shamattawa at $02: 49$. It again propagated westward a little. It is now evident that the difference between onset times as well as patterns on the meridian display of auroras at Little Grand Rapids and at Shamattawa in Fig. 1 is due to the difference in occurrence of bright northwestward auroral protrusions above Little Grand Rapids and Shamattawa.

\subsection{Example $B$}

Figure 7 shows dynamics of the example B aurora. As seen in the sequential pictures, the auroral structure of this example is complicated. Many auroral arcs were distributed above Little Grand Rapids and Shamattawa prior to the expansion. The faint aurora above Little Grand Rapids at 05:40 was a pulsating aurora. A clear auroral protrusion began to develop at 05:42 above Little Grand Rapids. Almost at the same time, or a little prior to this, other auroral protrusions occurred at the northern part of the sky of Fort Smith, Shamattawa and Great Whale River independently of the first. Between the protrusion above Little Grand Rapid and those in higher latitudes there were stable auroral arcs remaining unchanged until 05:46. After 05:47, the first protrusion above Little Grand Rapids shifted poleward as it brightened, and then a new protrusion was formed in the west of Shamattawa at 05:49. Here again, it is evident that the auroral expansion front consists of northwestward auroral protrusions as indicated by arrows in the figure. They repeat 


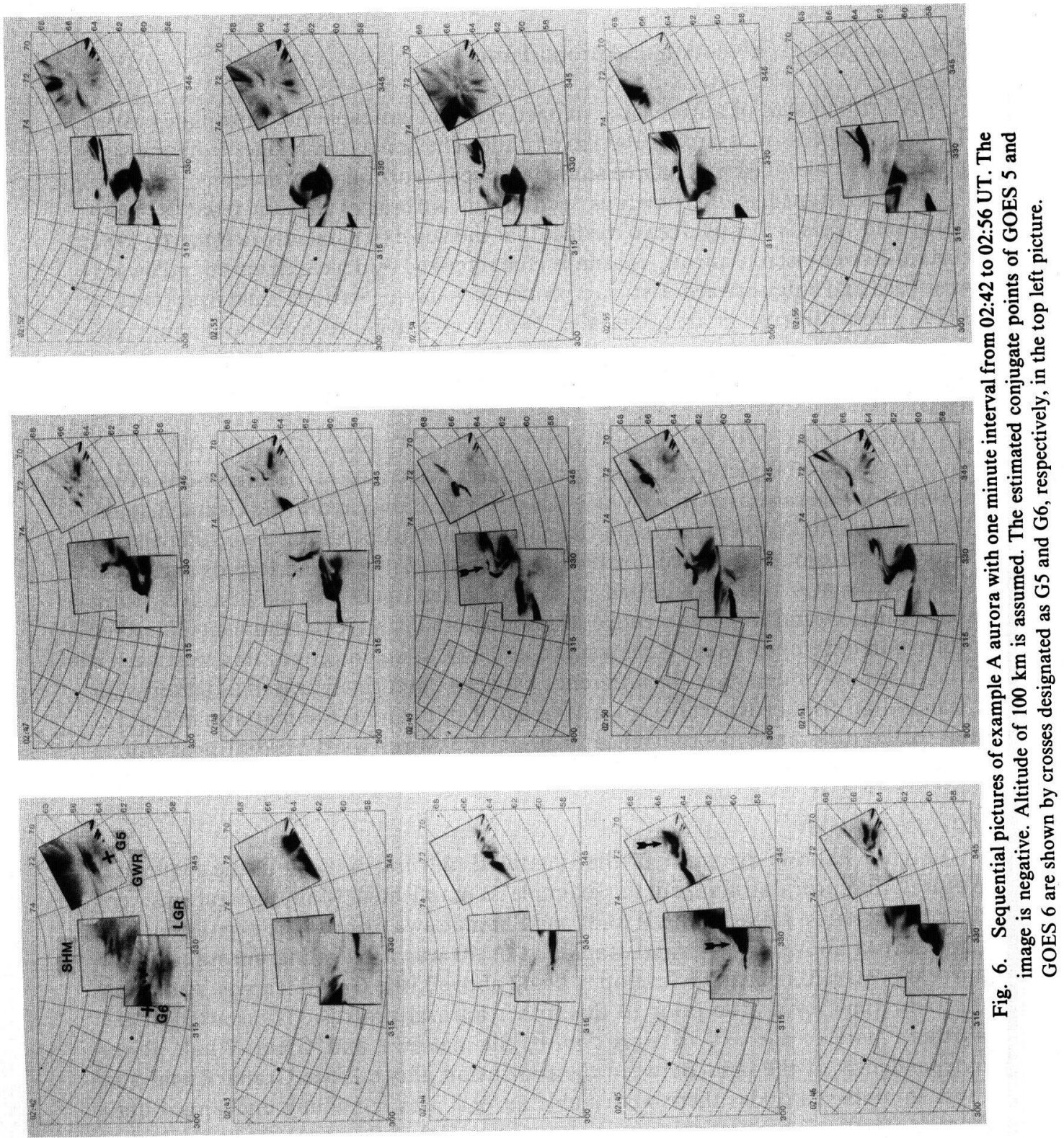




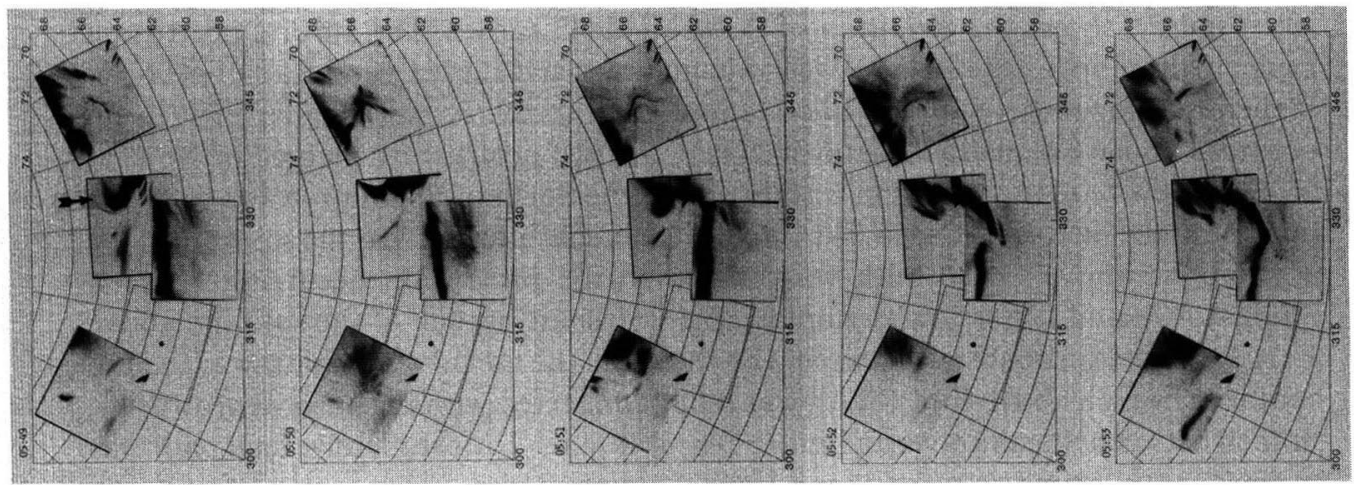

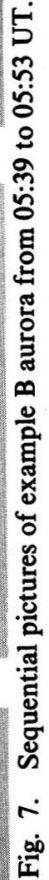
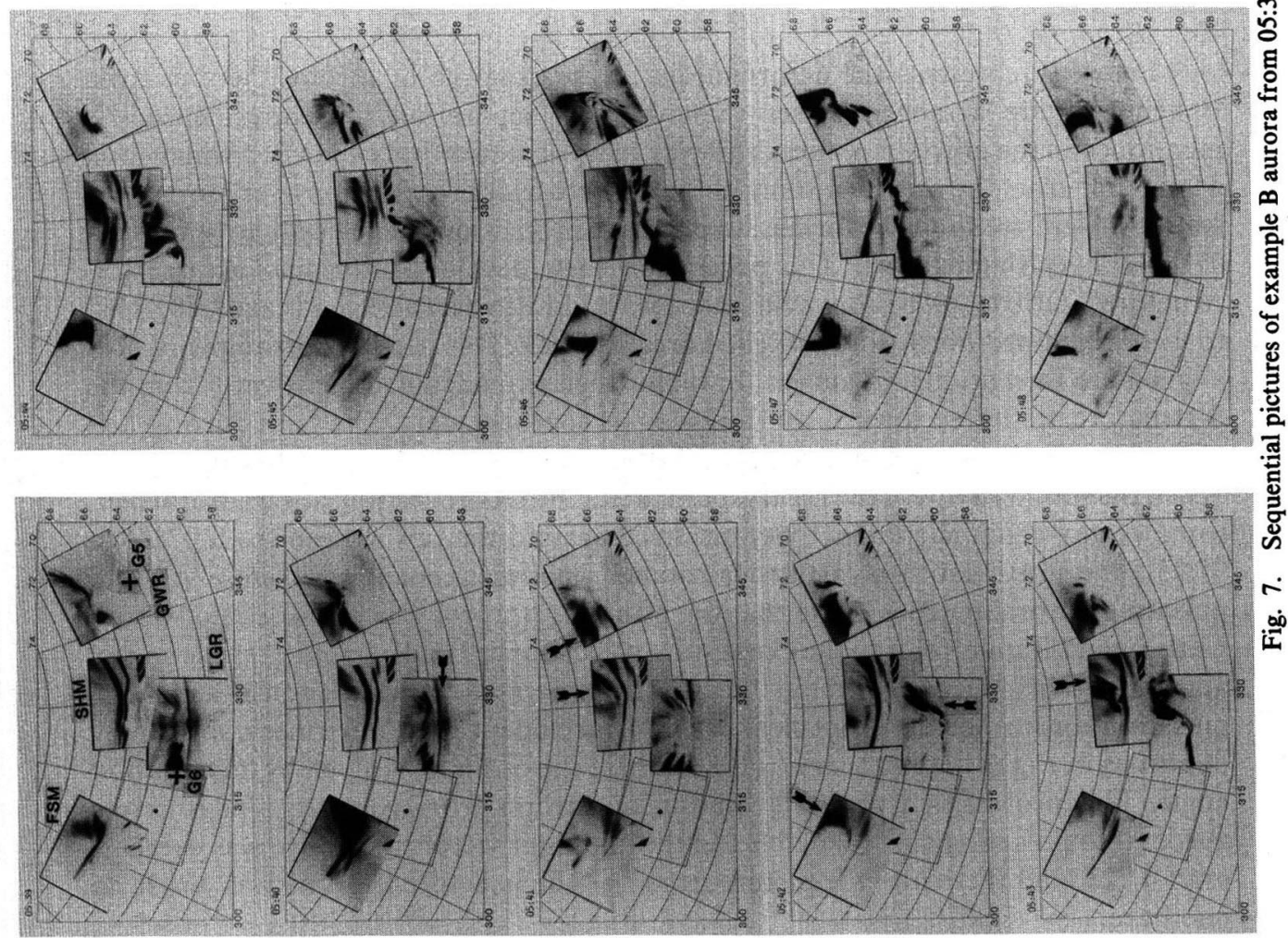
to develop and decay here and there along the larger scale expansion front.

\subsection{Example $C$}

Figure 8 shows the evolution of the example $\mathrm{C}$ aurora. The auroral protrusion began to develop in the east in between Shamattawa and Little Grand Rapids at 06:36. It then developed between the two stations until 06:39. A new smaller protrusion occurred above Shamattawa at 06:40. Then, the two protrusions merged into one at 06:42. A new fainter protrusion was formed in the north of Shamattawa at 06:43. In looking at the pictures from 06:34 to 06:38, it could be inferred that the splitting of the auroral arc above Fort Smith was related to the protrusion occurring between Shamattawa and Little Grand Rapids. The northeast branch of the split arc above Fort Smith was probably connected with the arc in the north of Shamattawa, and the southern branch above Fort Smith was likely connected with the auroral protrusion branch between Shamattawa and Little Grand Rapids. Unfortunately, La Ronge was overcast at that time, and the connections mentioned above were not confirmed.

\subsection{Example $D$}

Figure 9 represents the deformations of the example D aurora. Pictures from Poker Flat are arranged closer than the real separation for convenience. As mentioned in the previous section, this was an intricate auroral expansion which took a long time from the very beginning of the onset to a large expansion over most of the stations. Here, we show the formation of a large protrusion which began to develop at 07:13 above Shamattawa. The protrusion then developed forming a large "Sstructure"(OGUTI, 1975) above Shamattawa and Little Grand Rapids at 07:20. It led to well developed north-south aligned arcs at 07:23. This is a good example of N-S aligned arc formation. An auroral branch which extended southeastward from the S-structure, deflected toward southwest as its southern part. The faint auroral belt aligned in the east-west direction above Little Grand Rapids was a pulsating aurora. When the southern tips of the north-south arcs approached the pulsating auroral belt, some vortex-chain auroral activity occurred around the tips as seen from 07:22 to 07:25. The north-south arcs further rotated clockwise, changing themselves into pulsating auroral patches. Note that the pulsating aurora, which was located above Little Grand Rapids prior to the expansion, was enhanced and expanded as the vortex auroral activity decayed around the southern part of the north-south arcs. The pulsating auroral activity is not clear in Fig. 4 but evident at the third meridian display of aurora in Fig. 3 in OGUTI et al. (1988) where the ordinate is given by an elevation angle. This process is a typical evolution of auroras from vortex-chains (discrete auroras) to pulsating auroral patches in the midnight sector. La Ronge was overcast until 07:28, and therefore, the picture from La Ronge before the time was just for a reference.

\subsection{Example E}

Figure 10 shows the evolution of example E auroras. Again, pictures from Poker Flat are arranged closer than the real separation. This auroral protrusion occurred at 

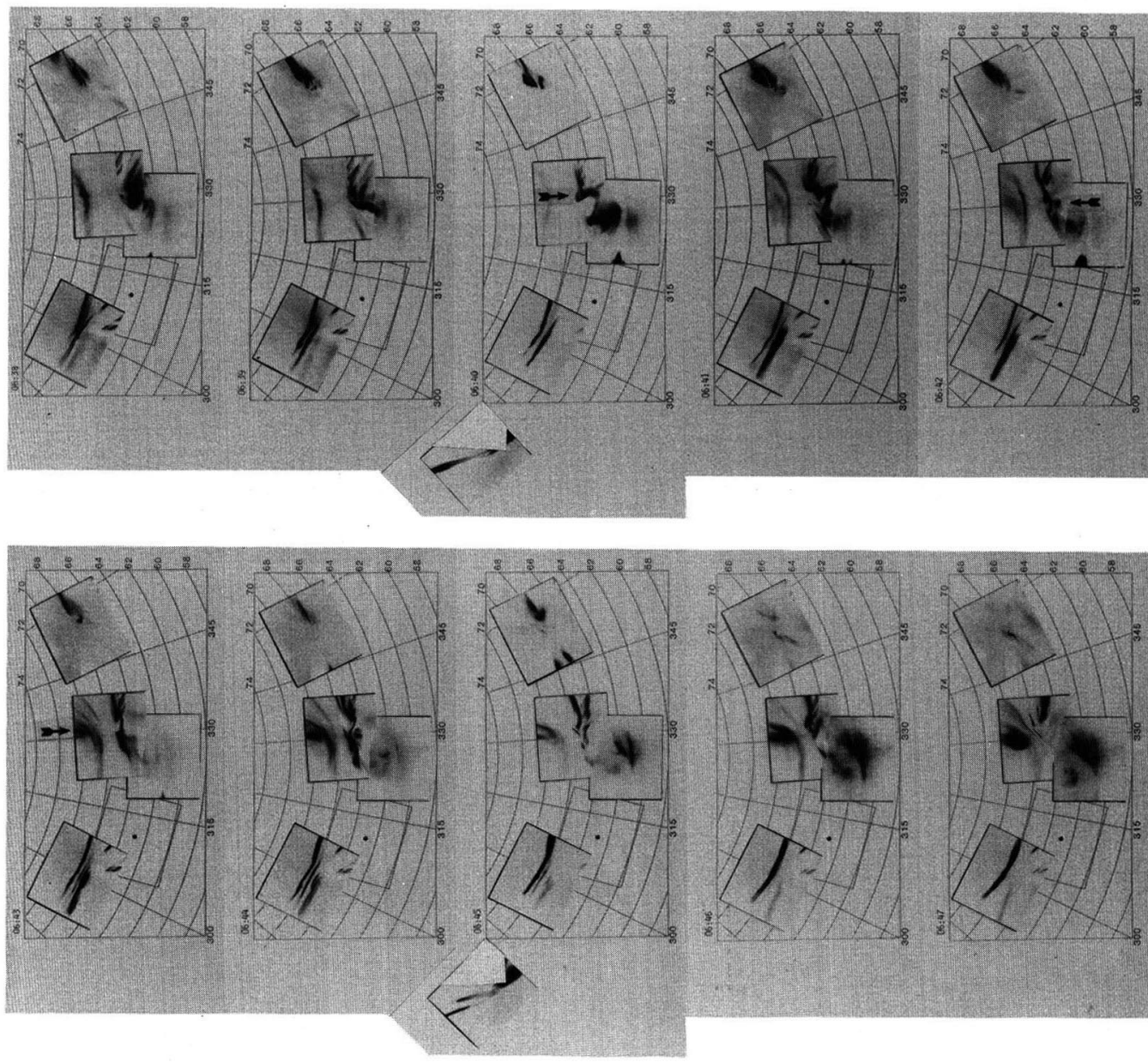

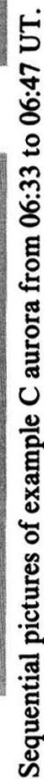
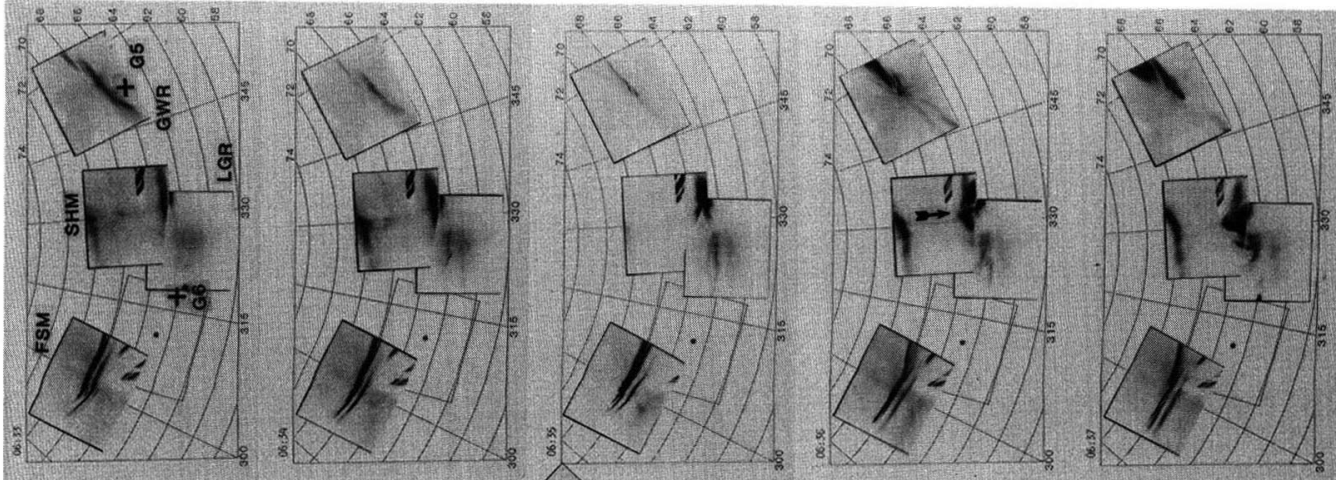

$\infty$ 
T. OGUTI et al.

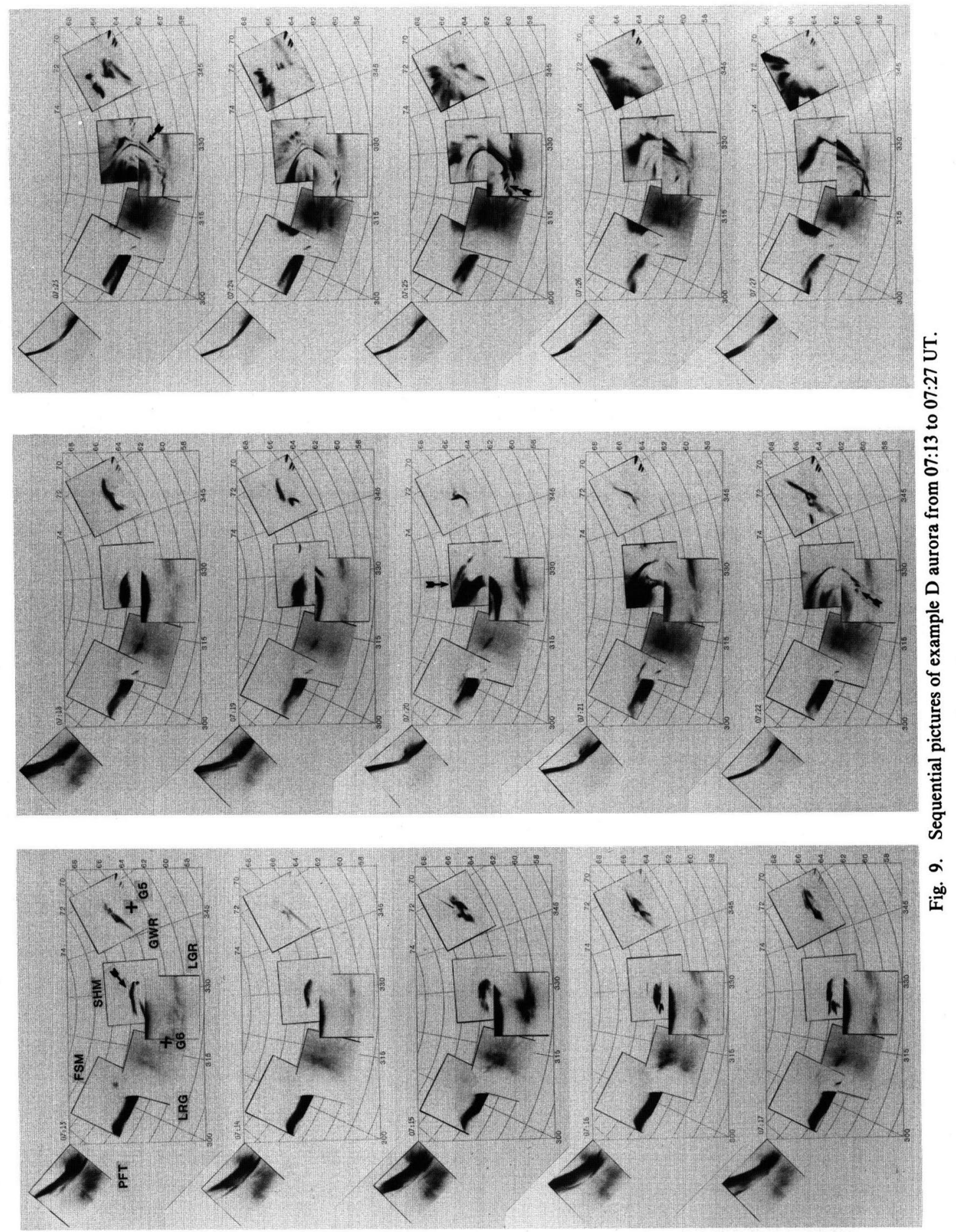




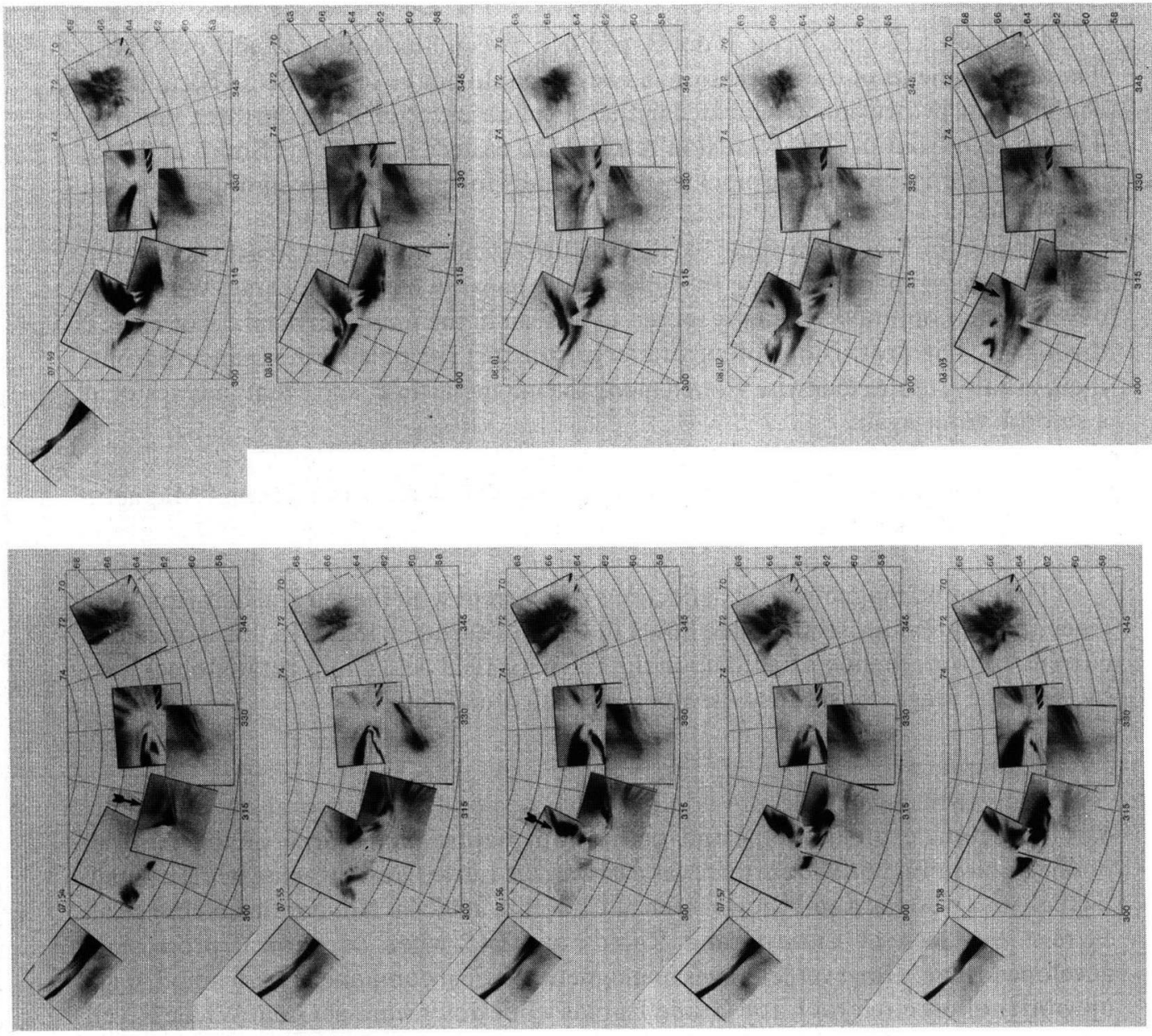

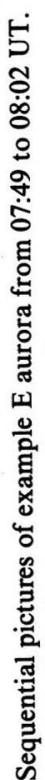

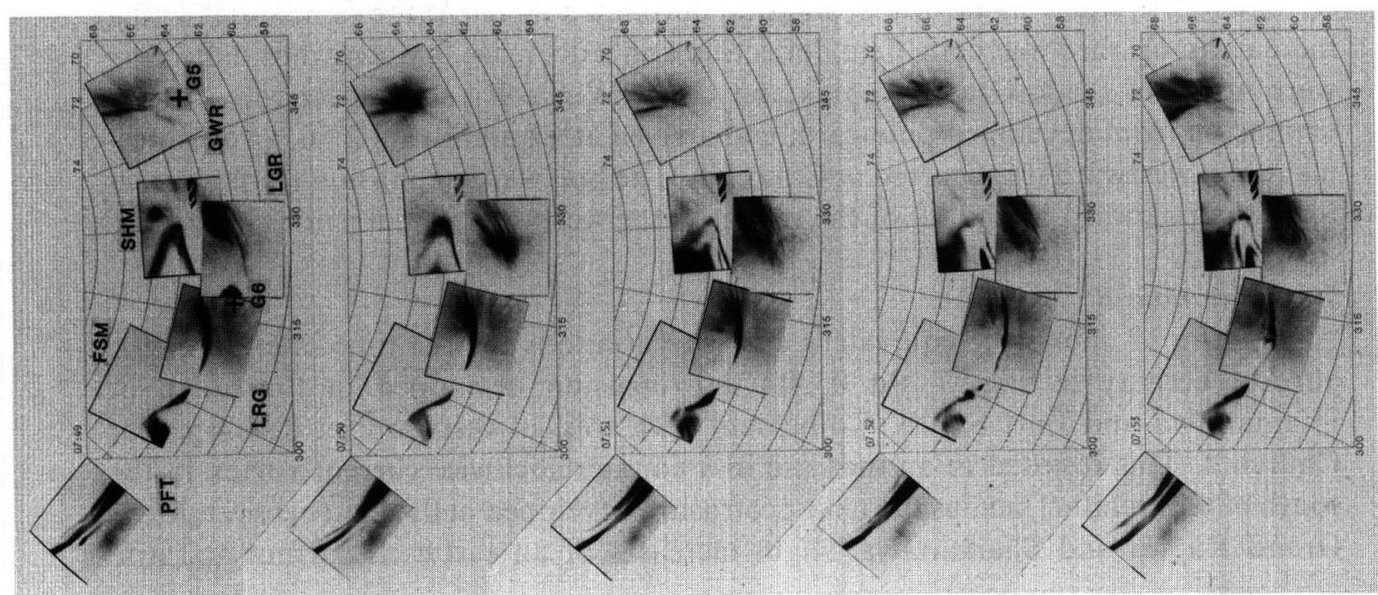

으

拄 
07:54 above La Ronge. Then, it developed in between Shamattawa and Fort Smith. The developments of the protrusion, however, could not be seen in detail because the center of the protrusion was located in the gap of observation from the three stations. The western front of the protrusion reached the eastern sky of Fort Smith at 07:56. The expansion front rotated clockwise, eventually forming a rather smooth arc again after 08:02.

As seen in Figs. 6 through 10, the northwestward auroral protrusions develop and decay here and there along the poleward expansion front of auroras. When they develop their luminosity usually increases as seen in the meridian displays of Figs. 1 through 5. The protrusions of aurora largely distort the poleward expansion front, then, usually rotate clockwise viewed along the magnetic field, and eventually result in a smooth front again.

5. Relationships between Large Scale Auroral Dynamics and Ground Magnetic Field Deflections

The ground magnetic field deflections concurrent with the auroral deformations given in the previous section are shown in Figs. 11 through 15. Here, the equivalent current vectors are shown based upon the magnetic field deflections rotated clockwise by $90^{\circ}$. The magnetic stations used here are listed in Table 1 .

\subsection{Example $A$}

Equivalent current variations in Fig. 11 correspond to the auroral activity in Fig. 6. The rectangle on the left-hand of the top picture is the area of the auroral observation in Fig. 6. The current was eastward at Little Grand Rapids while a small increase in a westward current was seen at Churchill at 02:44. No significant change of current was seen at Little Grand Rapids at 02:45 when an auroral protrusion developed there. However, changes in magnetic vertical component were noted, e.g., upward (hollow circle) at Little Grand Rapids while downward at Great Whale River (circle with cross). An enhancement of a westward jet current was seen at Great Whale River at 02:46 when an auroral protrusion developed there. At the same time further increase in upward magnetic field deflection and a decrease in downward deflection were noted at Little Grand Rapids and Great Whale River, respectively. As the expansion front developed poleward, and arrived at Churchill at 02:56, an enhancement of a westward jet occurred at Churchill. The poleward expansion front appears to be the poleward boundary of the region of the westward jet current.

\subsection{Example $B$}

Figure 12 shows the equivalent current variations for the time interval of the auroral activity in Fig. 7. At 05:40, a protrusion developed in the north of Shamattawa and Fort Smith. Coincident with this, a westward jet developed at Churchill. This resulted in an increase in a counterclockwise current vortex in the south of Churchill. Then, as the next protrusion developed at 05:42 in between Little Grand Rapids and Shamattawa, slight increases of an eastward current at Little 
Table 1. Lists of magnetic stations.

\begin{tabular}{|c|c|c|c|c|c|}
\hline \multirow[t]{2}{*}{ Station } & \multirow[t]{2}{*}{ Abbrev. } & \multicolumn{2}{|c|}{ Geographic } & \multicolumn{2}{|c|}{ Geomagnetic } \\
\hline & & lat. & long. & lat. & long \\
\hline Mould Bay & MLB & 76.3 & 240.6 & 80.6 & 263.1 \\
\hline Poker Flat & PFT & 65.1 & 212.5 & 65.1 & 259.7 \\
\hline Resolute Bay & RSB & 74.7 & 265.1 & 84.1 & 304.3 \\
\hline Cambridge Bay & CBB & 69.1 & 255.0 & 77.8 & 299.7 \\
\hline Yellowknife & YLK & 62.4 & 245.6 & 69.9 & 294.4 \\
\hline Fort Saint John & FSJ & 56.2 & 239.1 & 62.4 & 291.2 \\
\hline La Ronge & LRG & 55.2 & 254.7 & 64.9 & 310.8 \\
\hline Meanook & MEA & 54.6 & 246.7 & 62.6 & 300.9 \\
\hline Baker Lake & BKL & 64.3 & 264.0 & 75.1 & 320.1 \\
\hline Churchill & CHR & 58.8 & 265.9 & 70.3 & 326.0 \\
\hline Island Lake & ISL & 53.9 & 265.3 & 65.5 & 326.5 \\
\hline Little Grand Rapids & LGR & 52.0 & 264.5 & 63.5 & 325.8 \\
\hline Glenlea & GLL & 49.6 & 262.9 & 60.9 & 324.0 \\
\hline Great Whale River & GWR & 55.3 & 282.2 & 68.0 & 353.7 \\
\hline Ottawa & OTT & 45.4 & 284.3 & 58.5 & 356.0 \\
\hline Narsarsuaq & NAQ & 61.2 & 314.6 & 68.9 & 44.0 \\
\hline Saint Johns & STJ & 47.6 & 307.3 & 57.6 & 29.1 \\
\hline Isafjordhur & ISF & 66.1 & 336.9 & 69.0 & 70.1 \\
\hline Tjornes & TJO & 66.2 & 342.9 & 68.0 & 75.1 \\
\hline Husafell & HUS & 64.7 & 339.1 & 67.2 & 70.7 \\
\hline Ny Ålesund & NAL & 78.9 & 11.9 & 75.9 & 114.7 \\
\hline
\end{tabular}

Grand Rapids and a westward current at Churchill were noted. Then a large-scale auroral deformation occurred from 05:46 and developed westward covering Great Whale River, Shamattawa and Little Grand Rapids. This was accompanied by an increase in a northward current at Great Whale River, with increases in upward magnetic field deflection at Yellow Knife and Great Whale River. The development of the northward current could be related to the formation of the north-south aligned arcs above Great Whale River at that time.

\subsection{Example $C$}

Figure 13 shows equivalent current vectors for the example C. During the course of a protrusion development in between Little Grand Rapids and Shamattawa from 06:35 to 06:45, an eastward current developed at Little Grand Rapids. Increase in a westward current at Churchill at 06:44 lagged 4-5 minutes behind it. No significant change in current was found at 06:48 when a small protrusion appeared in the north of Shamattawa. The arrival of this expansion front at Poker Flat at 06:40 (in Fig. 3) was concurrent with an increase in an eastward (not westward) current and an upward magnetic field deflection there. Possibly reflecting the fact that the expansion was small, the current vectors at other stations did not change much for the time interval of this event. 


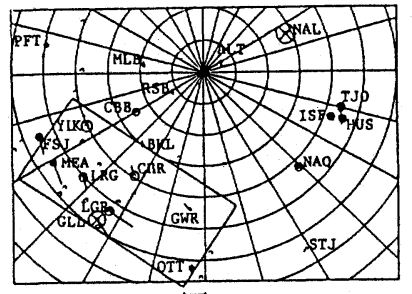

$86010702: 42 \quad 200 \mathrm{nT} / \mathrm{dl}$ V Z-half

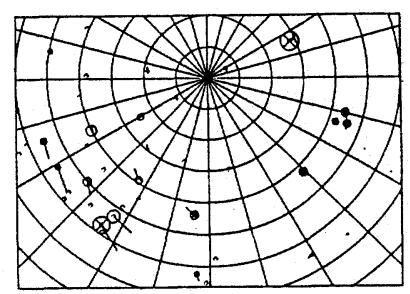

$86010702: 43200 \mathrm{nT} /$ div Z-half

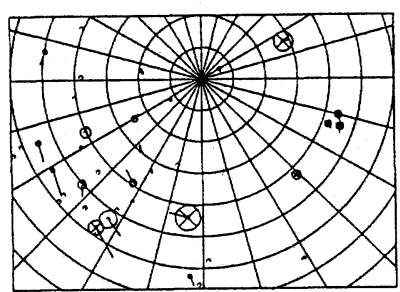

$86010702: 44200 \mathrm{nT} / \mathrm{div}$ Z-half

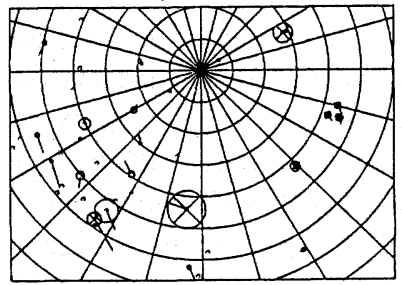

$86010702: 45200 \mathrm{nT} /$ div Z-half

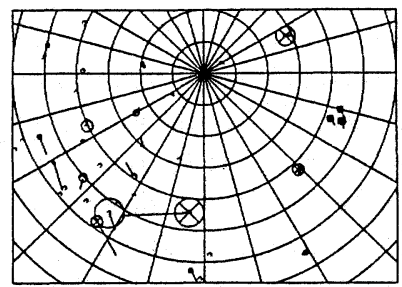

$86010702: 46200 \mathrm{nT} / \mathrm{div}$ Z-hale

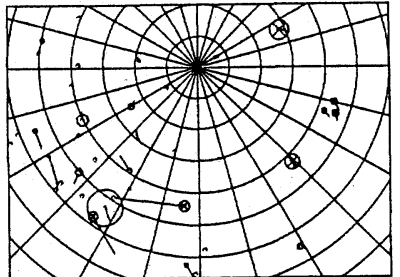

$86010702: 47200 \mathrm{nT} / \mathrm{div} Z$ Z-half

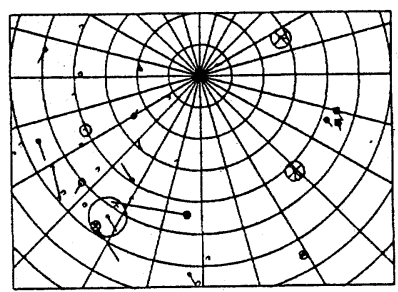

860107 02:48 200 nT/div Z-half

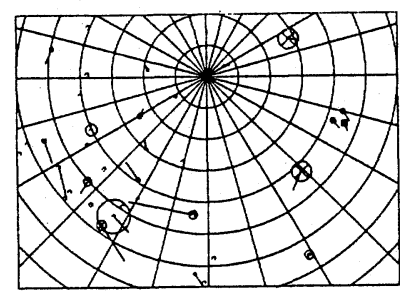

$86010702: 49 \quad 200$ nT/div Z-half

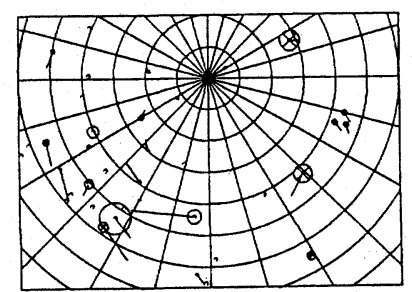

$86010702: 50200 \mathrm{nT} / \mathrm{d} 1 \mathrm{v}$ Z-half

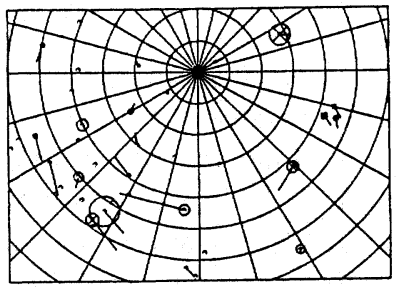

$86010702: 51200 \mathrm{nT} /$ div Z-half

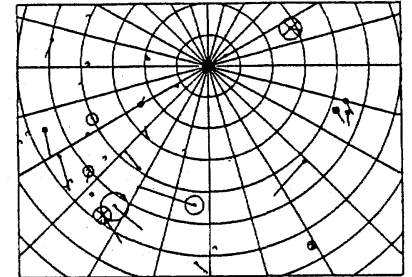

$86010702: 52 \quad 200$ nT/div z-hale

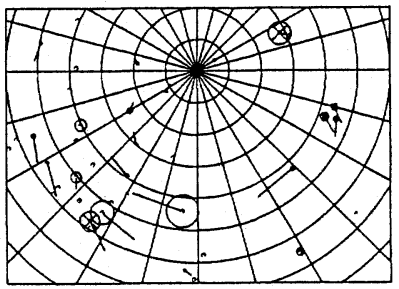

$86010702: 53200 \mathrm{nT} / \mathrm{div}$ Z-half

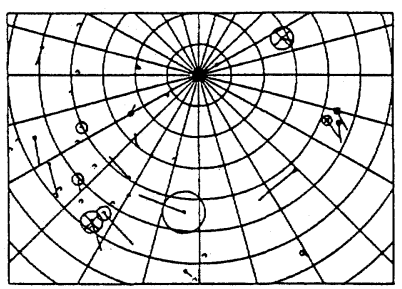

$86010702: 54 \quad 200$ nT/div Z-half

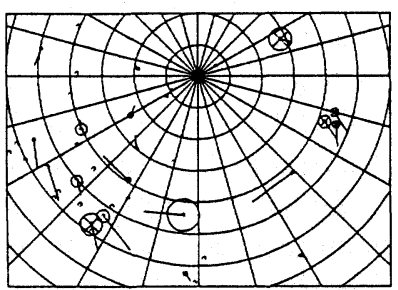

860107 02:55 200 nT/div Z-half

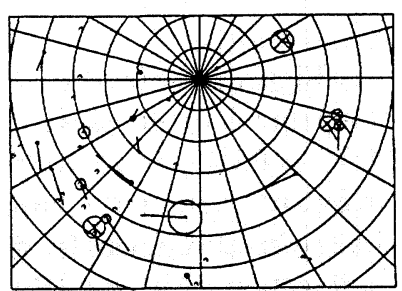

$86010702: 5620 \overrightarrow{n T / d 1 V}$ Z-half

Fig. 11. Time evolution of equivalent currents deduced from ground magnetic field deflections from 02:42 to 02:56 UT, corresponding to the evolution of example A aurora in Fig. 6. Arrows indicate equivalent current vectors. Circles represent the changes of the vertical component, hollow circle for upward deflection, and circle with cross for downward. The square in the top left picture shows the auroral observation area of Fig. 6. 


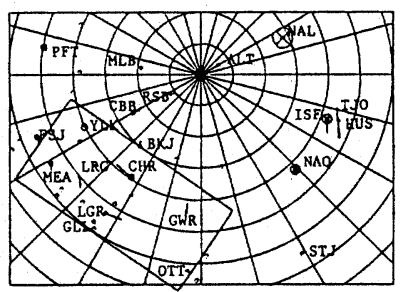

$86010705: 39200 \mathrm{nT} / \mathrm{d}$ iv z-half

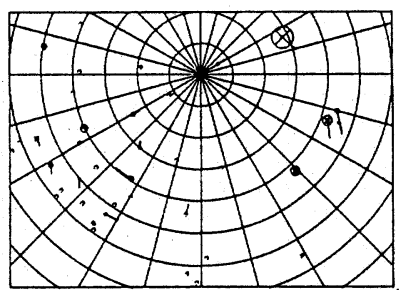

860107 05:40 200 nT/div Z-haif

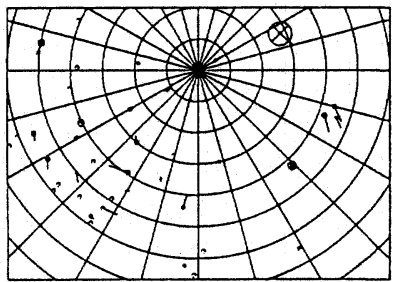

860107 05:41 200 nT/div Z-half

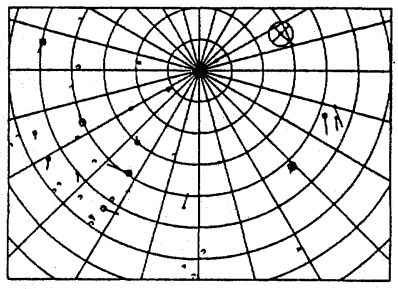

860107 05:42 200 nT/div Z-half

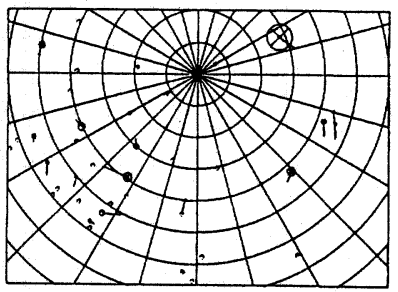

$86010705: 43200$ nT/div Z-nalf

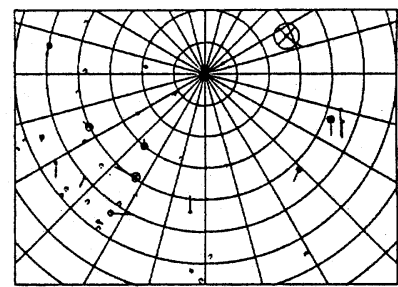

860107 05:44 200 nT/div Z-half

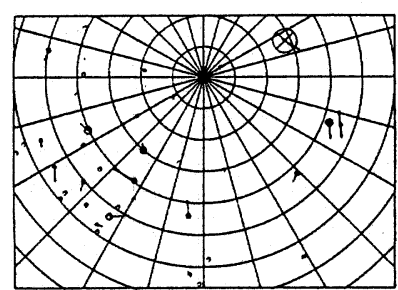

$86010705: 45 \quad 200 \mathrm{nT} / \mathrm{div}$ Z-half

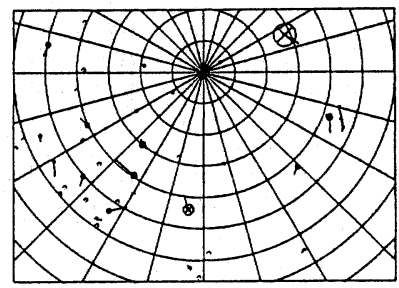

860107 05:46 200 nT/div Z-half

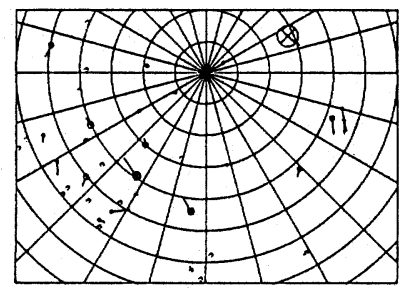

$86010705: 47200 \mathrm{nT} /$ div Z-half

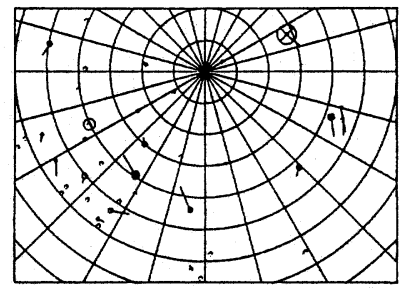

$86010705: 48 \quad 200 \mathrm{nT} / \mathrm{div}$ Z-half

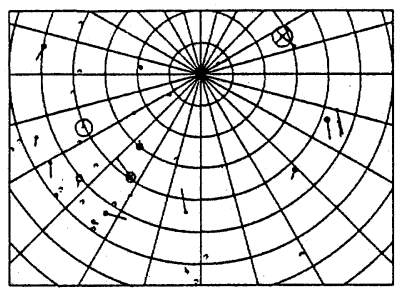

$86010705: 49200$ nT/div Z-half

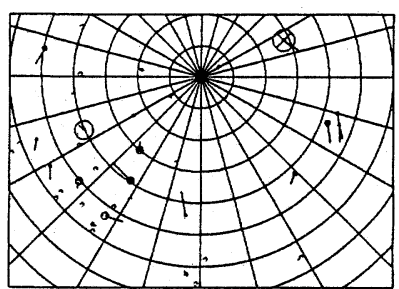

860107 05:50 200 nT/div Z-half

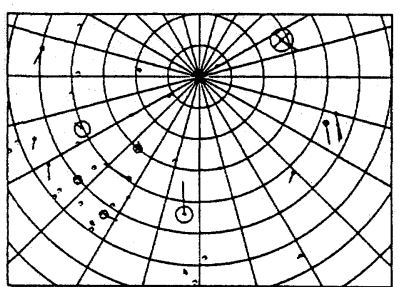

$86010705: 5120 \overrightarrow{0} \mathrm{nT} / \mathrm{div} Z$-hale

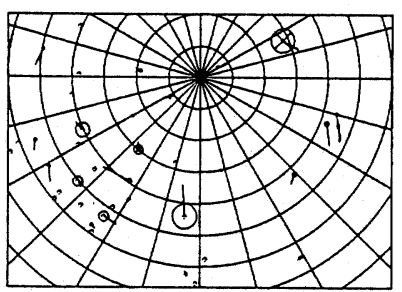

$86010705: 52 \quad 200$ nT/d1v Z-half

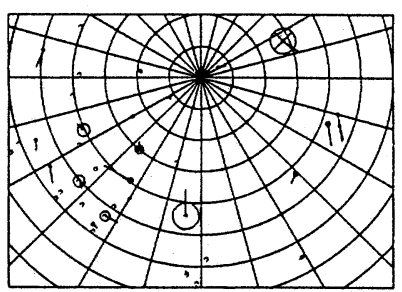

$86010705: 53200 \mathrm{nT} / \mathrm{div} Z$-half

Fig. 12. Time evolution of the equivalent currents from 05:39 to 05:53 UT, corresponding to the evolution of example B aurora in Fig. 7. 


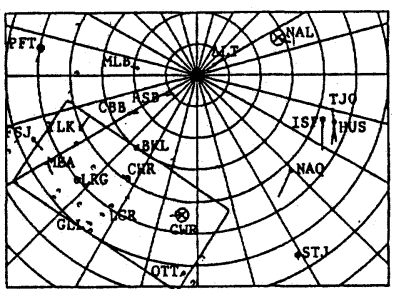

$86010706: 33200 \mathrm{nt} / \mathrm{div}$ Z-half

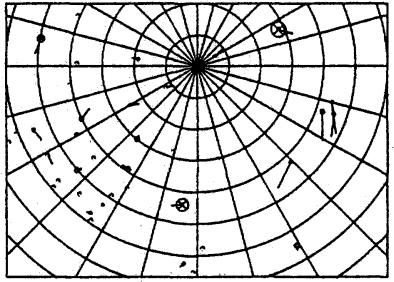

$86010706: 34200 \mathrm{nT} / \mathrm{d}$ iv Z-half

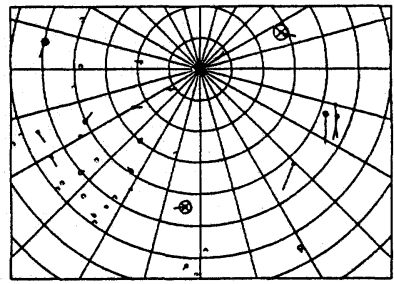

$86010706: 35 \quad 200$ nT/div Z-half

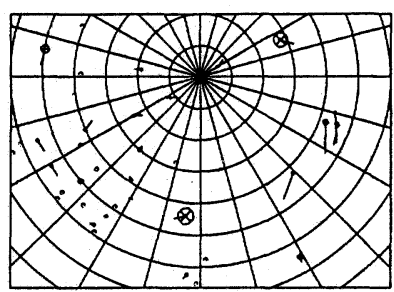

$86010706: 36200 \mathrm{nT} / \mathrm{div} \mathrm{Z}$-half

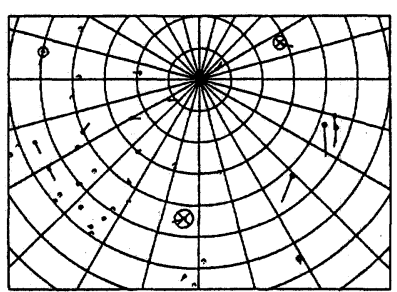

$86010706: 37200 \mathrm{nT} / \mathrm{d}$ iv Z-half

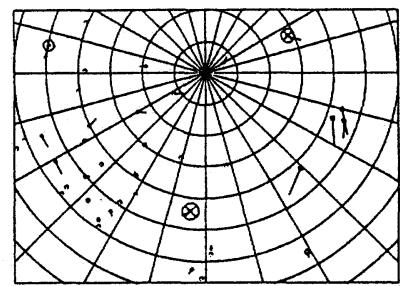

860107 06:38 200 nT/div Z-half

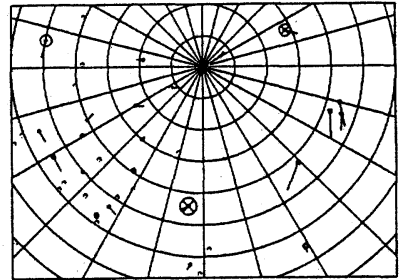

$86010706: 39200 \mathrm{nT} / \mathrm{div} Z \mathrm{Z}$-half

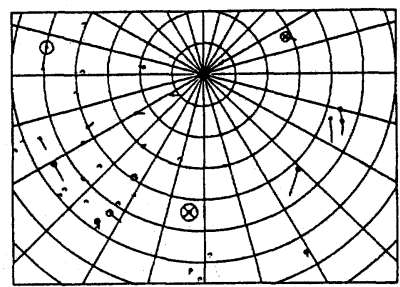

$86010706: 40 \quad 200$ nT/div z-half

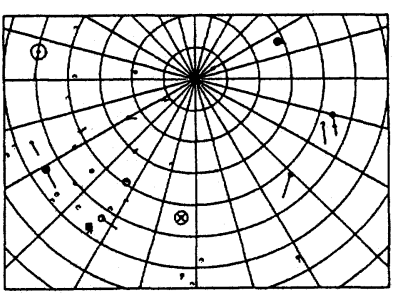

$86010706: 41200 \mathrm{nT} / \mathrm{div} Z \mathrm{Z}$-hale

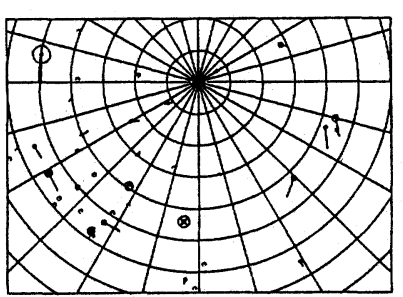

860107 06:42 200 nT/div Z-half

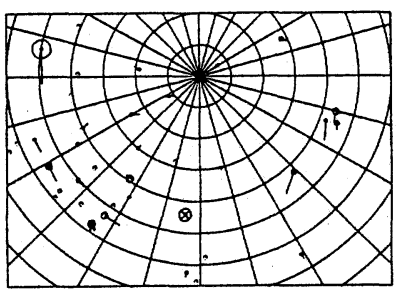

860107 06:43 $200 \mathrm{nt} / \mathrm{d}$ iv Z-half

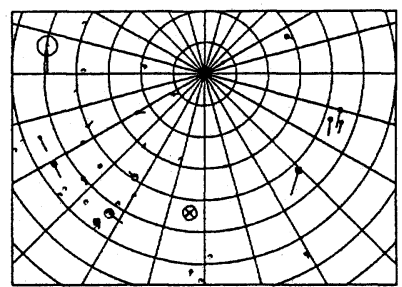

$86010706: 44200$ nT/div Z-half

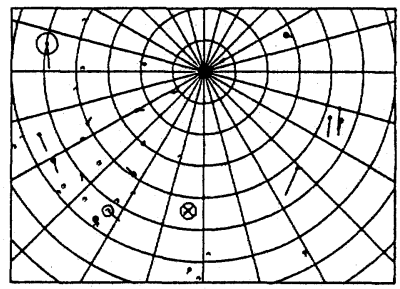

$86010706: 45200 \mathrm{nT} / \mathrm{d}$ iv Z-half

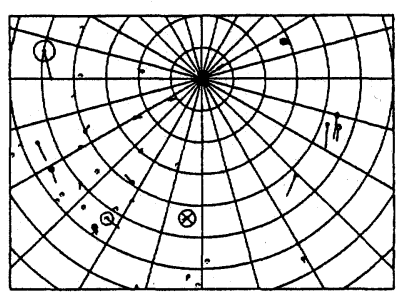

$86010706: 46200 \mathrm{nT} / \mathrm{d}$ iv $\mathrm{Z}$-half

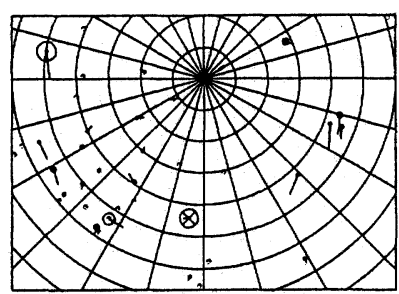

860107 06:47 200 nT/div Z-half

Fig. 13. Time evolution of the equivalent currents from 06:33 to 06:47 UT, corresponding to the evolution of example $\mathrm{C}$ aurora in Fig. 8. 


\subsection{Example $D$}

Figure 14 shows the development and decay of the equivalent current for the time of development of the second large auroral protrusion in the example $\mathrm{D}$ above Shamattawa. It was evident that the enhancement of a westward current at Churchill was coincident with the development of this protrusion above Churchill. From 07:20 to $07: 24$, when it developed above Churchill, a westward current developed together with an enhancement of the upward magnetic field deflection at Churchill. Then, the current vector at Churchill gradually rotated clockwise towards the northwest as the north-south aligned arcs also rotated clockwise.

\subsection{Example E}

Figure 15 shows variations of the equivalent current vectors for the time interval of the auroral evolution in Fig. 10. Here, the auroral protrusion at Fort Smith was accompanied by enhancements of a westward current at Yellow Knife and a counterclockwise vortex current in the south of it.

The relationships between auroral dynamics and equivalent currents are rather complicated as described above. A tendency, however, could be summarized as follows: Northwestward auroral protrusions develop and decay along a poleward expansion front of auroras during the course of an auroral expansion with enhancements in luminosity. Strong local westward jet currents are related to the auroral protrusions at night. The magnetic field variations concurrent with the protrusion developments are quite similar to the stepwise developments of a substorm mentioned by WIENS and ROSTOKER (1975), but not so systematic as theirs, occurring here and there. In the dusk sector, an eastward (not westward) current increases around the auroral protrusions. Enhancements in counterclockwise vortex currents are observed in these auroral protrusions all the time from the dusk to the midnight.

It is worth noting that the equivalent current does not significantly change even when an auroral protrusion develops if the magnetic station is hundreds $\mathrm{km}$ away from the protrusion. This suggests that the westward electrojet associated with the auroral protrusion is spatially limited, and, consequently, little magnetic effect occurs beyond a certain distance. This point will be discussed in the next section again in connection with the similar local nature of the magnetic field variations observed by synchronous satellites.

6. Relationships between Auroral Dynamics and Magnetic Field Perturbations at Synchronous Orbit

The developments of the auroral protrusions are compared with the magnetic field perturbations observed by GOES 5 and 6 satellites. The magnetic footpoint of GOES 5 estimated by the IGRF 1985 together with the Tsyganenko-Usmanov external field model (TSYGANENKO and USMANOV, 1982) was located about $250 \mathrm{~km}$ south of Great Whale River. The footpoint, therefore, was within the coverage of auroral observation from Great Whale River in Figs. 6 to 10. The footpoint of GOES 


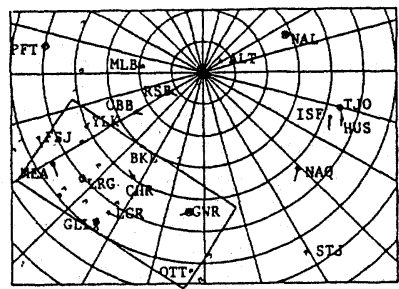

$86010707: 13200 \mathrm{nt} / \mathrm{div} Z$ Z-half

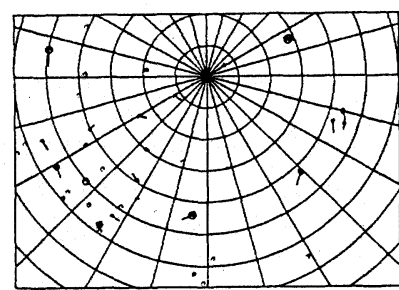

$86010707: 14 \quad 200 \mathrm{nT} / \mathrm{div}$ Z-half

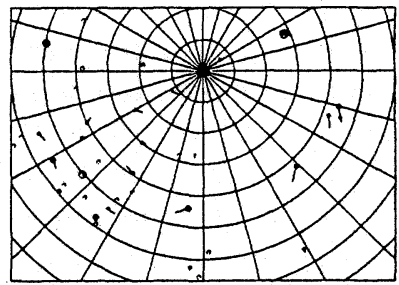

860107 07:15 200 nT/div Z-half

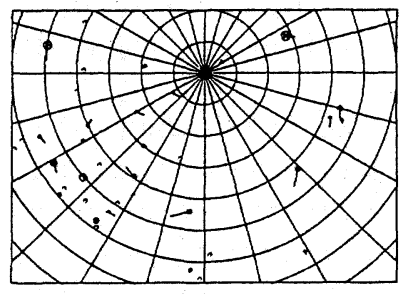

860107 07:16 200 nT/div Z-half

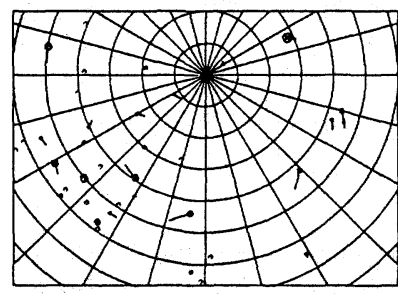

$86010707: 17200 \mathrm{nT} / \mathrm{div}$ Z-half

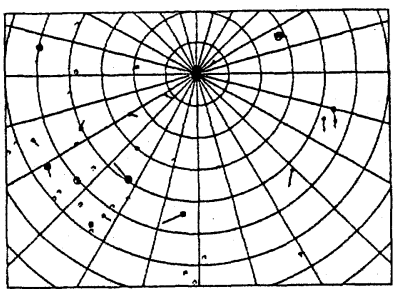

$86010707: 18 \quad 200 \mathrm{nT} / \mathrm{div} Z$ Z-half

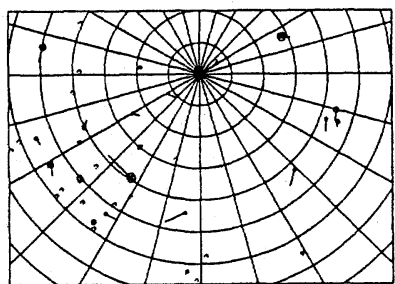

860107 07:19 200 nT/div Z-half

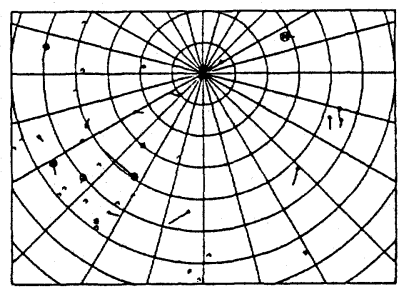

$86010707: 20200 \mathrm{nT} / \mathrm{div}$ Z-half

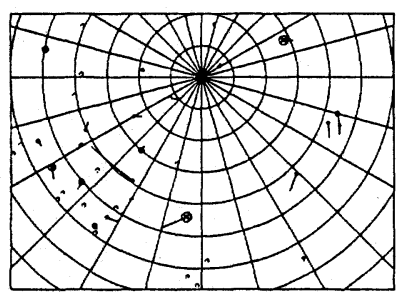

860107 07:21 200 nT/div Z-half

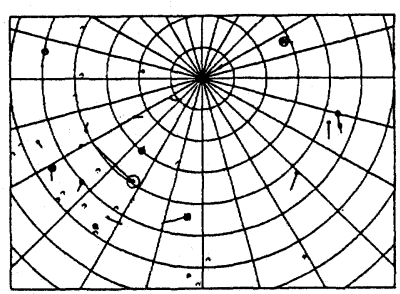

860107 07:22 200 nT/div Z-hale

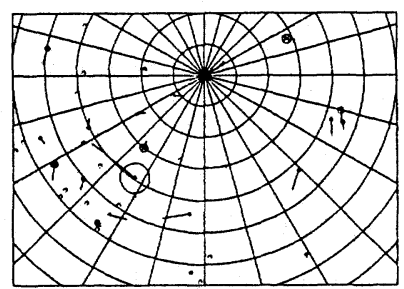

860107 07:23 200 nT/div Z-half

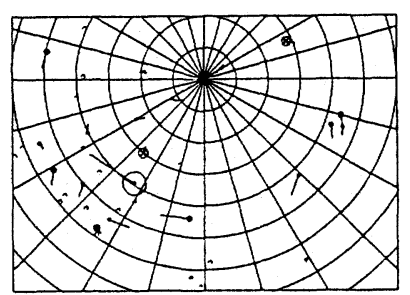

$86010707: 24 \quad 200 \mathrm{nT} / \mathrm{div}$ Z-half

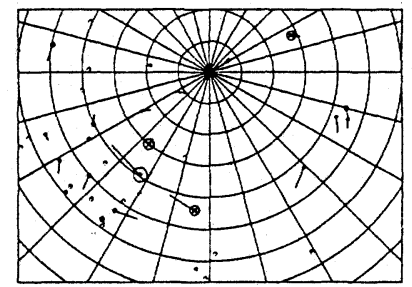

$860107 \quad 07: 25 \quad 200$ nT/div Z-half

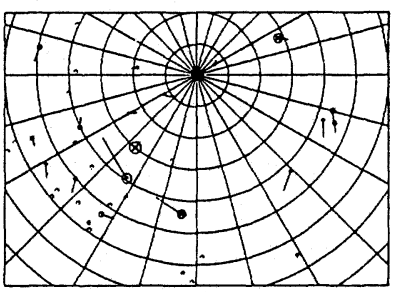

860107 07:26 200 ni/div Z-hale

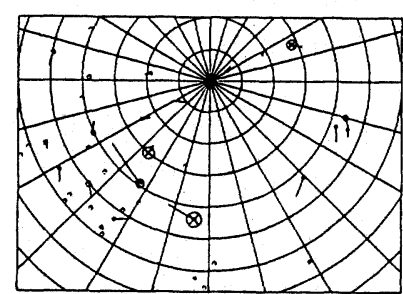

860107 07:27 200 nt/div Z-half

Fig. 14. Time evolution of the equivalent currents from 07:13 to 07:27 UT, corresponding to the evolution of example D aurora in Fig. 9. 


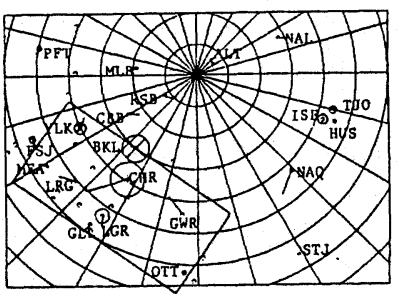

$86010707: 49200$ nT/div Z-half

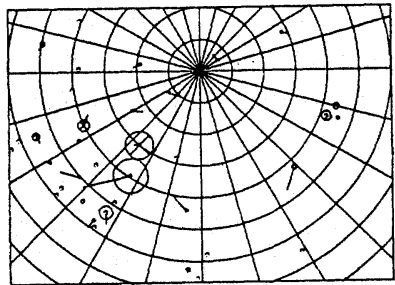

$860107 \quad 07: 50 \quad 200 \overrightarrow{n T}_{\text {ndiv Z-half }}$

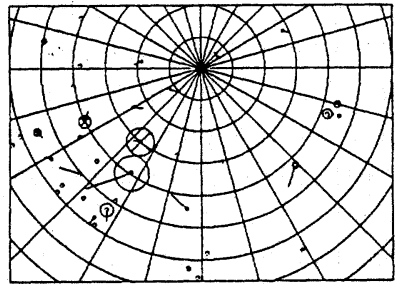

$86010707: 51200 \mathrm{nT} / \mathrm{div} Z$-half

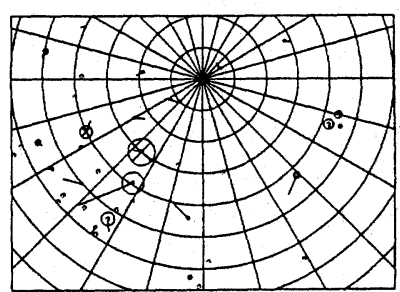

$86010707: 52 \quad 200 \mathrm{nT} / \mathrm{div}$ Z-half

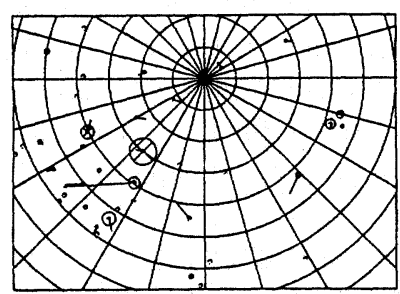

$86010707: 53200 \mathrm{nT} / \mathrm{div}$ Z-half

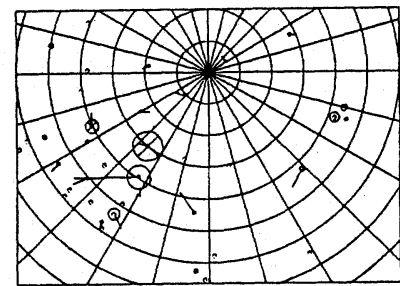

$86010707: 5420 \overrightarrow{0}$ T/div Z-haif

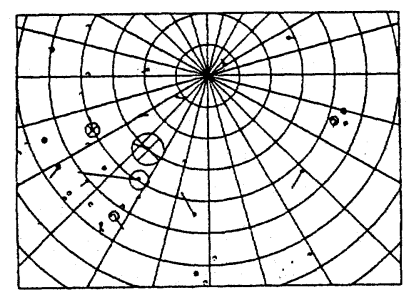

$86010707: 5520 \widehat{0}_{\text {nT }}$ ddv Z-half

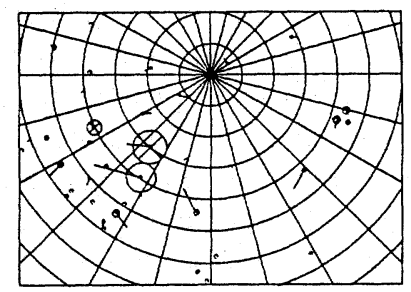

$86010707: 56 \quad 200 \mathrm{nT} / \mathrm{div}$ Z-half

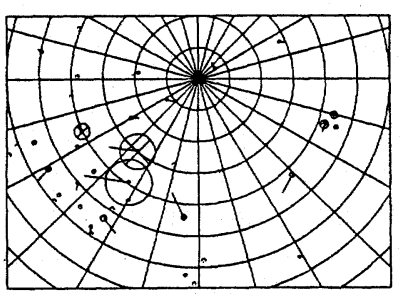

$86010707: 57200 \mathrm{nT} / \mathrm{div}$ Z-haif

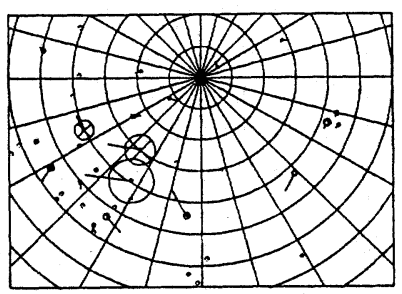

$86010707: 58 \quad 200 \mathrm{nT} / \mathrm{div}$ Z-half

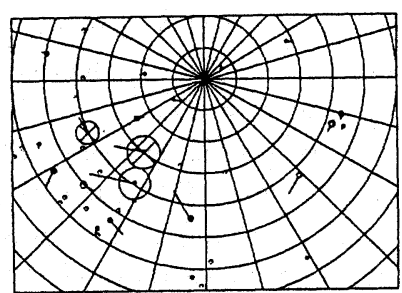

$86010707: 59200 \mathrm{nT} /$ div Z-half

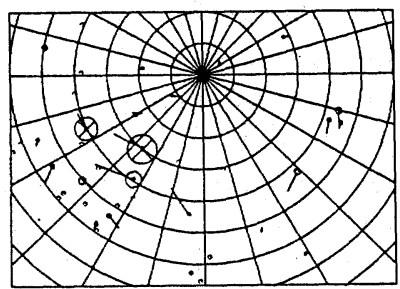

860107 08:00 200 nT/div Z-half

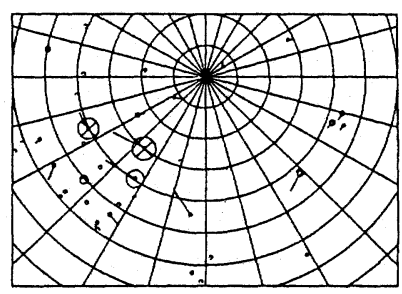

$86010708: 01200$ nT/div Z-half

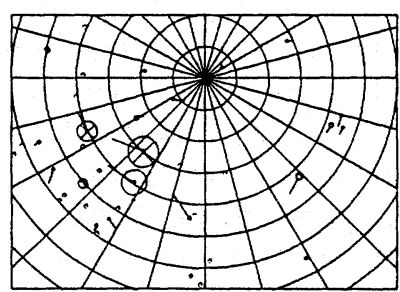

860107 08:02 200 nT/div Z-hale

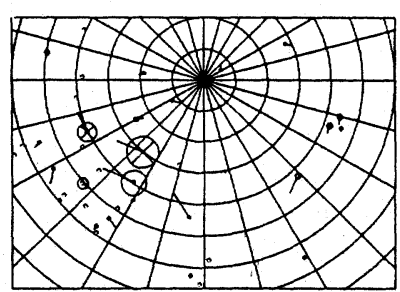

$86010708: 03 \quad 200$ nT/div Z-half

Fig. 15. Time evolution of the equivalent currents from 07:49 to 08:02 UT, corresponding to the evolution of example E aurora in Fig. 10. 
6 was located about $350 \mathrm{~km}$ westnorthwest of Little Grand Rapids and $350 \mathrm{~km}$ eastsoutheast of La Ronge. These footpoints are shown by crosses in the first picture of Figs. 6 to 10.

Magnetic field data obtained by the two satellites are given in Figs. 16 to 18 in the $H$ (antiparallel to the dipole), $V$ (outward, perpendicular to the dipole axis) and $D$ (azimuthal, eastward) coordinates. As seen in these figures, five characteristic changes in magnetic field occur at 02:45, 05:42, 06:39, 07:26 and 07:57 UT at GOES 6 and at 02:38, 05:48, 06:33, 07:24 and 08:05 UT at GOES 5.

Comparing these changes at synchronous orbit with the auroral evolution as shown in Figs. 6 through 10, we find that the characteristic magnetic field variations at the synchronous satellites are closely related to the formations of the auroral protrusions which develop in the vicinity of their magnetic conjugate points. For example, event A shows that the formation of the auroral protrusion above Little Grand Rapids at 02:45 is coincident with an abrupt decrease in the $V$ component and concurrent increases in the $H$ and $D$ components at GOES 6 (see Fig. 16). The protrusion did not yet reach the estimated conjugate point of GOES 6 at that time. When the aurora covered the conjugate point at 02:50, the magnetic field at GOES 6 had already been largely deflected. The concurrence of the magnetic field changes at GOES 6 with development of the auroral protrusion above Little Grand Rapids, despite the spatial separation of $350 \mathrm{~km}$ between the estimated conjugate point and the aurora, suggests two possibilities. One was that the distance $(350 \mathrm{~km})$ was within the range of magnetic field perturbations due to field-aligned currents interlinked with the protrusion, and the other was that GOES 6 was passed by a current sheet connected with another auroral part more west of the protrusion, in accidental coincidence with the development of the protrusion. However, there was no active auroral branch around the estimated conjugate point at that time. The accidental coincidence is unlikely.

The magnetic field changes at GOES 5 at 02:38, led those at GOES 6 by 7 minutes. We could expect that an auroral protrusion probably developed in the south of Great Whale River at 02:38, although the aurora was out of the view from Great Whale River at that time. A bright auroral arc which came up into the field of view at Great Whale River from the south, 5 minutes later, at 02:43, would support this idea. This suggests that the real conjugate point of GOES 5 was far south of the estimated conjugate point (indicated by a cross). Note that the second protrusion which developed above Shamattawa at 02:49 had no significant correspondent in magnetic field changes at GOES 6 . This suggests that the protrusion was too far away from the conjugate point and GOES 6 was not located within the range where magnetic field changes could be detected.

The example B shows similar relationships between magnetic field changes at GOES 6 and auroral deformations above Little Grand Rapids. As seen in Fig. 17, the magnetic field changes began at 05:42 at GOES 6, when a well-defined auroral protrusion developed in the east of Little Grand Rapids. Here again the auroral protrusion had not yet reached the estimated conjugate point of GOES 6 at that time. At 05:46 when the protrusion probably reached it, magnetic field changes at GOES 6 

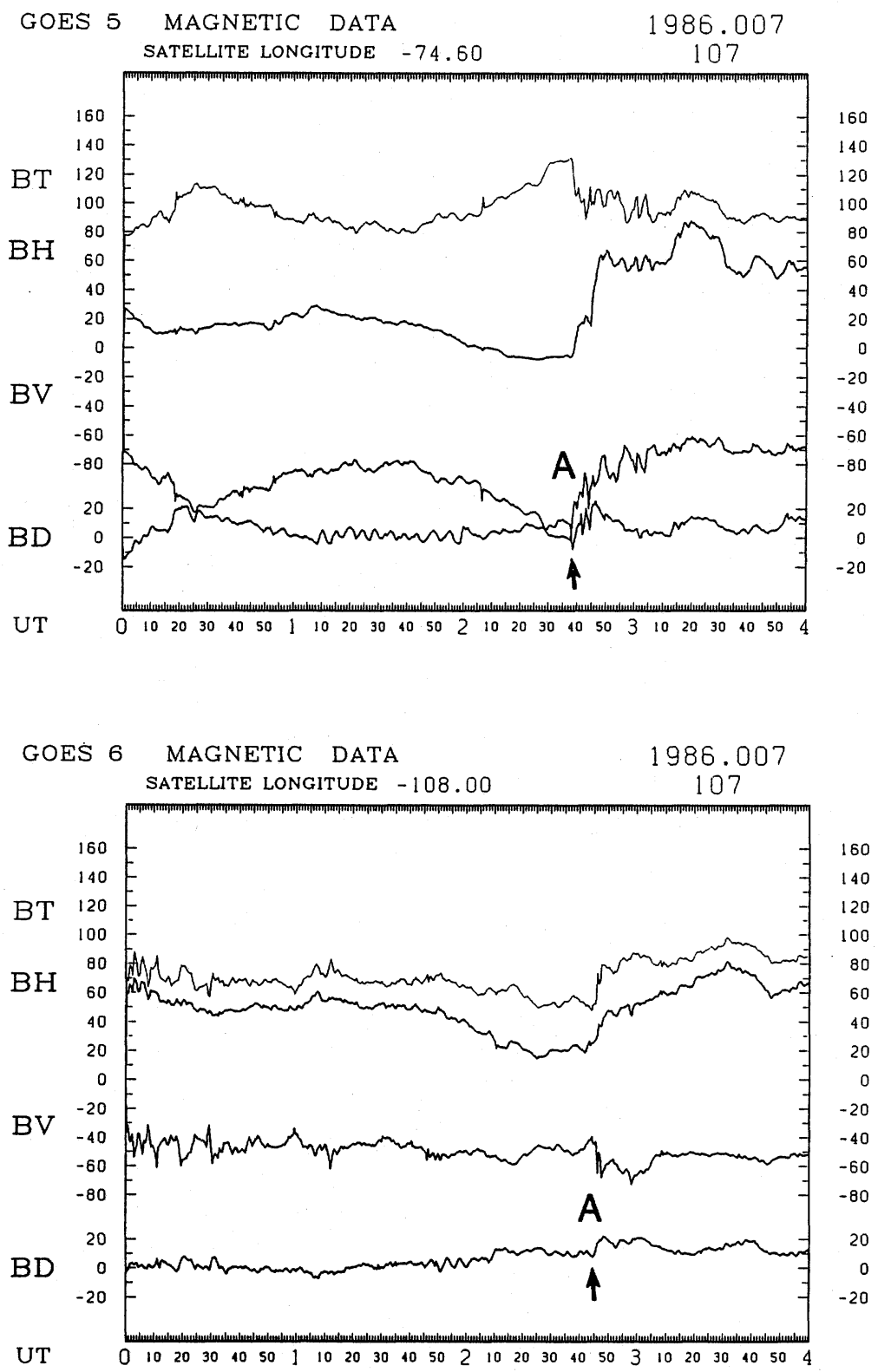

Fig. 16. Magnetic field changes at GOES 5 (upper) and GOES 6 (lower) from 00:00 to 04:00 UT on January 7, 1986. The $T$ (total intensity), $H$ (antiparallel to the geomagnetic dipole axis), $V$ (outward perpendicular to the geomagnetic dipole axis) and $D$ (azimuthal eastward) components are shown. Event $\mathrm{A}$ is designated as $\mathrm{A}$. 

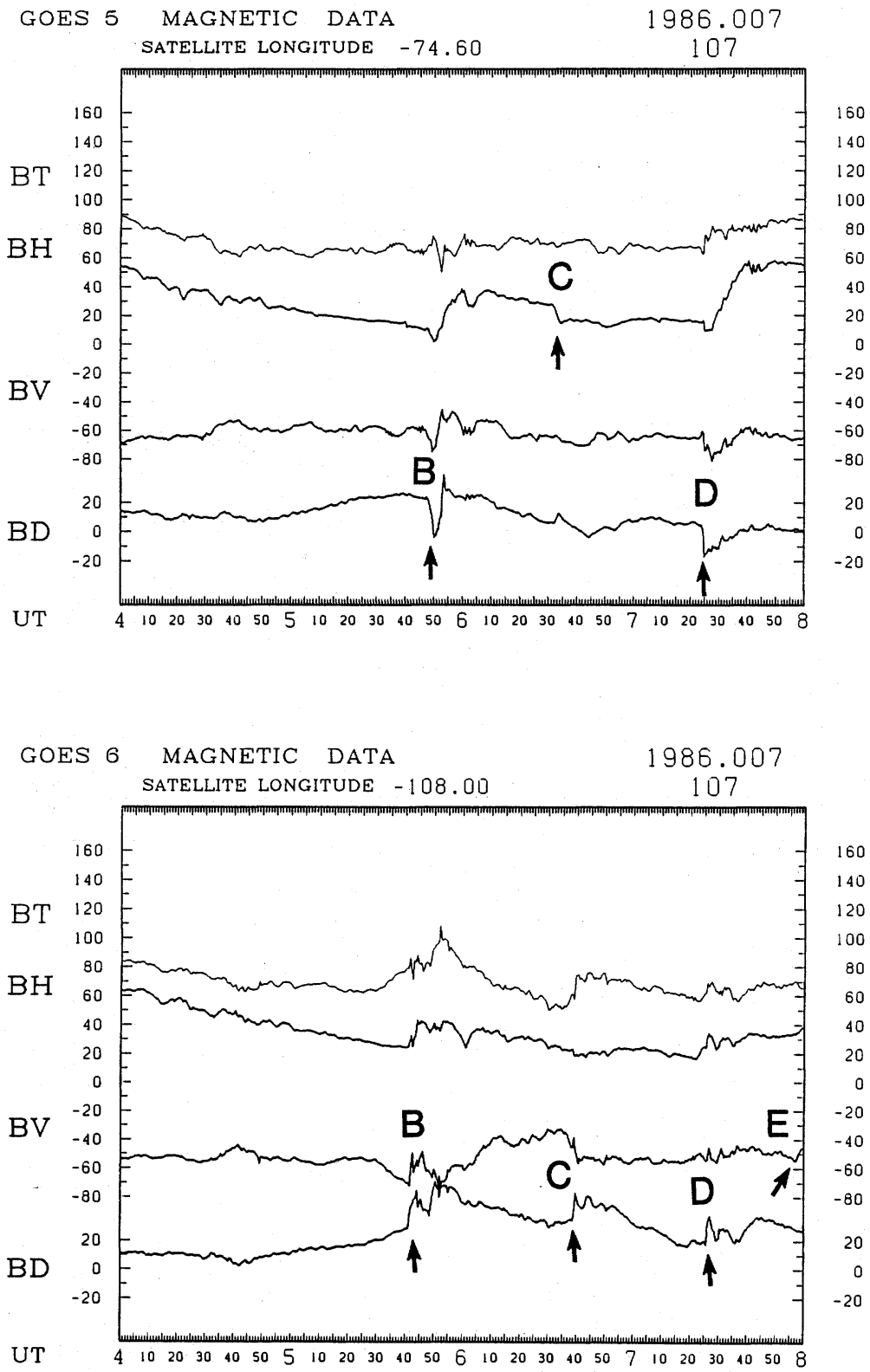

Fig. 17. Magnetic field changes at GOES 5 (upper) and GOES 6 (lower) from 04:00 to 08:00 UT on January 7, 1986. The $T$ (total intensity), $H$ (antiparallel to the geomagnetic dipole axis), $V$ (outward perpendicular to the geomagnetic dipole axis) and $D$ (azimuthal eastward) components are shown. Events $\mathrm{B}$ to $\mathrm{E}$ are designated as B, C, D and E. 

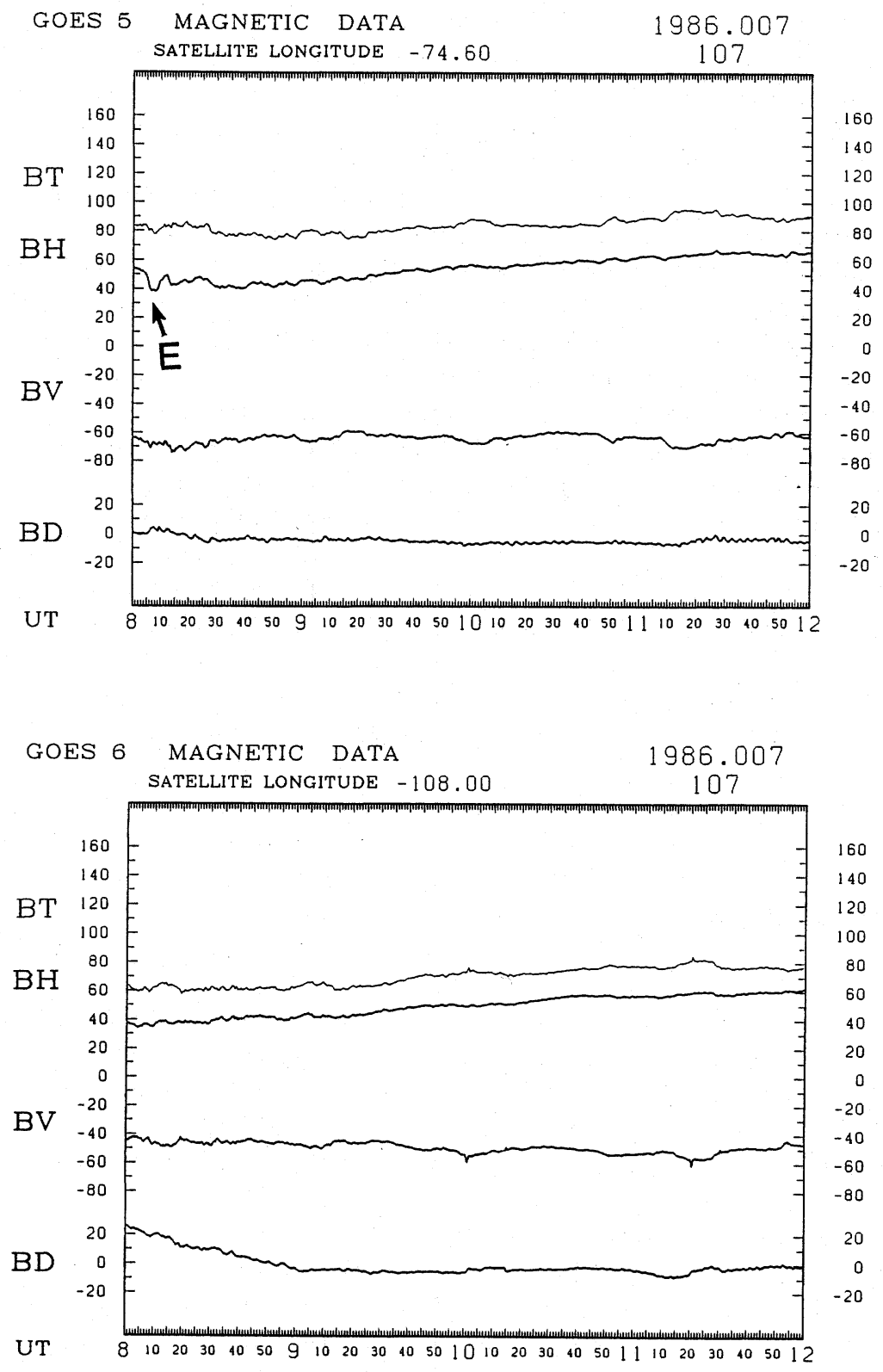

Fig. 18. Magnetic field changes at GOES 5 (upper) and GOES 6 (lower) from 08:00 to 12:00 UT on January 7, 1986. The $T$ (total intensity), $H$ (antiparallel to the geomagnetic dipole axis), $V$ (outward perpendicular to the geomagnetic dipole axis) and $D$ (azimuthal eastward) components are shown. Event $\mathrm{E}$ is designated as $\mathrm{E}$. 
had already been developed. The second change at 05:49 could correspond to the enhancement in auroral luminosity concurrent with the formation of the second large protrusion in the west of Shamattawa. The magnetic field change at GOES 6 seen at 05:49 could be related to the formation of the second large protrusion, or to the poleward crossing of the western part of the bright auroral arc at the conjugate point. Since magnetic field changes were also seen at GOES 5 at the same time (05:49), the second protrusion may had another auroral branch in the south of Great Whale River, again south of the estimated conjugate point. Another possibility was that injected plasma cloud was large enough to cover the two satellites at the same time, since the second protrusion was so large, covering from Shamattawa to Great Whale River as seen in the pictures from 05:49 to 05:53.

The example $\mathrm{C}$ was rather a small expansion. Still, the characteristic magnetic field change at 06:39 at GOES 6 could be related to the formation of the auroral protrusion between Little Grand Rapids and Shamattawa at 06:37. The expansion was small, and probably no active aurora was present in the south of Great Whale River. The idea was supported by the fact that no significant variation occurred at GOES 5 except small decreases in the $H$ component at 06:33. The 2 minutes difference between the formation of the protrusion (06:37) and the magnetic field change at GOES 6(06:39) could indicate that the magnetic effect of the field-aligned current was limited within a certain range of the current. It was reasonable that the magnetic field changes occurred at GOES 6 as the protrusion developed westward and approached the estimated conjugate region.

The example D was a large protrusion which developed above Shamattawa at 07:20. Magnetic field changes at GOES 6 occurred at 07:25, 5 minutes behind the development of the auroral protrusion. This was probably due to the fact that the protrusion developed above Shamattawa too far north of Little Grand Rapids, the magnetic conjugate area of GOES 6 . The magnetic field changes at GOES 6 were coincident with the developments of vortex-chain auroral activity around the southern tip of the north-south aligned arc covering the estimated magnetic footpoint of GOES 6. We would like to emphasize that the well-defined auroral protrusion above Shamattawa at 07:20 has no clear correspondent magnetic field changes both at GOES 5 and GOES 6. This again suggests that the field-aligned current associated with the auroral protrusion could locally close, and its magnetic effect could not be detected by the synchronous satellite beyond a certain distance.

The example E protrusion at 07:54 started to develop in the north of La Ronge far away from the magnetic footpoint of GOES 6. As the protrusion developed between La Ronge and Fort Smith at 07:57 further away from the conjugate point, a small increase in the $V$ component was noted at GOES 6. Probably because of the large distance between the aurora and the conjugate point, the magnetic field changes were small and not characteristic as those of the previous examples.

In summarizing the relationships between auroral evolution and magnetic field changes at GOES 5 and 6, we can claim that the characteristic magnetic field changes at synchronous orbit occur when the auroral protrusions develop in the vicinity of the magnetic footpoint of the satellite. Note that the magnetic field changes are not 
significant at the synchronous orbit when the protrusion develops hundreds $\mathrm{km}$ away from the magnetic footpoint as exemplified by the large protrusion at 07:20 UT of the example D. Similar relationships are also seen in the dawn sectors. As NISHITANI and OGUTI (1988) show, the characteristic magnetic field changes occur at synchronous orbit only when an eastward expansion front of an expansion aurora approaches the conjugate meridian of the satellite. The magnetic field changes due to field-aligned currents, which are interlinked with the auroral structures, are spatially limited, and could be detected only within a certain range. This idea is also supported by the fact that the onsets of the magnetic field changes at GOES 5 and 6 are usually different by several minutes. The coincidence of the onsets at the two satellites at 07:24 UT is most likely accidental.

\section{Conclusion and Discussion}

The development and decay of the northwestward auroral protrusions are the essential characteristics of the poleward expansion front of an expansion aurora. The protrusions are accompanied by local westward electrojets in the pre-midnight to midnight sectors. In the dusk sector, however, they are accompanied by eastward jets. All the protrusions, whether the jet is westward or eastward, are accompanied by counterclockwise vortex currents around them. The current vortex indicates a potential depression there. The potential depression is essentially connected with the upward (outward) field-aligned current. These observations are all in agreement with the results obtained by BAUMJOHANN et al. (1981). An important point here is that the spatial extent of the jet current, especially that of the westward jet is locally limited, being probably confined within or in the vicinity of the protrusion.

In space, sudden changes in magnetic field occur at synchronous orbit when an auroral protrusion develops in the vicinity of the conjugate point. The coincidence strongly suggests direct connection between the auroral protrusion with a vortex current and upward field-aligned current observed around GOES 5 and 6. Since the auroral protrusion develops preferentially in the northwestern part of an expansion aurora, this result is in agreement with the distribution of field-aligned currents measured by IMP 4 and 5 (FAIRFIELD, 1973). The rather poor coincidence between field changes at GOES 5 and those at GOES 6, together with the fact that the magnetic changes are observed only when an auroral protrusion develops in the conjugate area, again suggests that the magnetic field changes in space, related to the auroral protrusion, are spatially confined. The field aligned currents appear to locally close such that little magnetic effect is observed beyond a certain distance.

One might wonder if the magnetic field variations at synchronous orbit could really be direct effects of the local field-aligned currents which are interlinked with the auroral structures within and in the vicinity of auroral protrusions. The synchronous orbit is normally located far inside the magnetospheric region where the auroral protrusions are linked to. However, the concurrence of auroral activity and the magnetic field variations at synchronous satellites, as well as the localized nature of the magnetic field fluctuations both on the ground and at satellites, strongly suggests 
the direct linkage of the field-aligned currents at synchronous orbit and auroral protrusions. This is probably due to the fact that the protrusions here occur in an active period of time ( $K p=4$ to $6-)$, in conjunction with the fact that the geomagnetic latitudes of GOES 5 and 6 , in this sector, are quite remote from the equator, located at approximately $12^{\circ}$ and $9^{\circ}$, respectively.

Another possibility, however, is not yet disclaimed. It is that the magnetic field variations at synchronous orbit, coincident with the development of the auroral protrusion, may be due to injected hot plasma clouds which come from the auroral protrusion regions. The concurrence between the activation of southern tip of a north-south aligned arc and the magnetic field variations at GOES 6, as seen in Event $\mathrm{D}$, could be an example of this possibility. We must closely examine not only the protrusions but also fainter auroral structures around protrusions if they have any relationship with fast variations in magnetic field at synchronous orbit. At the present moment we could safely state that the protrusion-related auroral structures are likely interlinked with the field-aligned currents which produce magnetic field changes at synchronous orbit.

So far we have discussed the magnetic effects of the probable field-aligned currents at synchronous orbit. The observation also shows that the concept of the disruption of the cross-tail current is not always valid as seen in the deflection of the $V$ component. That is, most of the events, except A at GOES 5, show negative changes of the $V$ component in the night sector, in contrast to the broadly accepted idea that the magnetic field is modified into "dipole-like" configuration associated with the formation of the "current wedge"(e.g., MCPHERRON et al., 1973; NAGAI, 1982, 1987). The magnetic field changes at synchronous orbit, of course, are caused from the changes in field-aligned currents, cross-tail currents, ring currents and the magnetization currents of the injected plasma. The heating and/or acceleration of particles in a certain tail region, interlinked with the auroral protrusion, inevitably produce the change in pressure balance in the magnetosphere. The problem here, therefore, should be to find the total magnetic effects of these currents.

One intention of this study was to find a possibility to accurately determine the field line connection between a synchronous satellite and a point on the ground by comparing the magnetic field changes at the satellite and auroral deformations. At the present phase of the study, however, it is not yet fully successful because of the difficulty to locate the field-aligned currents relative to the satellite as well as to determine the structure of the field-aligned currents. A method similar to correlation analysis between magnetic field changes at a satellite and that on the ground by GREENWALD et al. (1981) may also be applied to the auroral activities.

The authors acknowledge financial support for the Global Aurora Dynamics Campaign from the Science Division, Ministry of Education, Science and Culture, Japan (grant 59042004, $60041014,61043013)$. Thanks are also due to financial support for the observation in Spitzbergen, coordinated with the Global Aurora Dynamics Campaign, from Kyoikusha, LTD. The authors are indebted to all the members of Geophysics Research Laboratory, University of Tokyo, for their assistance in preparing the instruments for the Campaign. 


\section{REFERENCES}

BARFIELD, J. N., C. S. LIN, and R. L. MCPHERRon, Observations of magnetic field perturbations at GOES 2 and GOES 3 during the March 22, 1979, substorms: CDAW 6 analysis, J. Geophys. Res., 90, 1289-1295, 1985.

Baumjohann, W., R. J. Pellinen, H. J. Opgenoorth, and E. Nielsen, Joint two-dimensional observations of ground magnetic and ionospheric electric fields associated with auroral zone currents: Current systems associated with local auroral break-ups, Planet. Space Sci., 29, 431-447, 1981.

CAUDAL, G., Field-aligned currents deduced from EISCAT radar observations and implications concerning the mechanism that produce region 2 currents, J. Geophys. Res., 92, 6000-6012, 1987.

FAIRFIELD, D. H., Magnetic field signatures of substorms on high-latitude field-lines in the nighttime magnetosphere, J. Geophys. Res., 78, 1553-1562, 1973.

Greenwald, R. A., A. D. M. WALKer, and M. CANDIDI, Use of hydromagnetic waves to map geomagnetic field lines, J. Geophys. Res., 86, 11251-11257, 1981.

Iijima, T. and T. A. Potemra, The amplitude distribution of field-aligned currents at northern high latitudes observed by TRIAD, J. Geophys. Res., 81, 2165-2174, 1976.

Iijima, T. and T. A. Potemra, Large-scale characteristics of field-aligned currents associated with substorm, J. Geophys. Res., 83, 599-615, 1978.

KAmide, Y. and S.-I. AKASOFU, The auroral electrojet and global auroral features, J. Geophys. Res., 80, 3583-3602, 1975.

KAMIDE, Y. and S.-I. AKASOFU, The location of the field-aligned currents with respect to discrete auroral arcs, J. Geophys. Res., 81, 3999-4003, 1976.

KAMIDE, Y. and A. D. RICHMOND, Ionospheric conductivity dependence of electric fields and currents estimated from ground magnetic observations, J. Geophys. Res., 87, 8331-8337, 1982.

KAMIDE, Y. and G. RosTOKER, The spatial relationship of field-aligned currents and auroral electrojets to the distribution of nightside auroras, J. Geophys. Res., 82, 5589-5608, 1977.

Kamide, Y., J. D. Craven, L. A. Frank, B. H. Ann, and S.-I. Akasofu, Modeling substorm current systems using conductivity distributions inferred from DE auroral images, J. Geophys. Res., 91, 11235-11256, 1986.

Kokubun, S. and R. L. MCPherron, Substorm signatures at synchronous altitude, J. Geophys. Res., 86, 11265-11277, 1981.

McPherron, R. L., C. T. Russell, and M. P. Aubry, Satellite studies of magnetospheric substorms on August 15, 1968: 9. Phenomenological model for substorms, J. Geophys. Res., 78, 3131-3149, 1973.

NAGAI, T., Observed magnetic substorm signatures at synchronous altitude, J. Geophys. Res., 87, 4405-4417, 1982.

NAGAI, T., Field-aligned currents associated with substorms in the vicinity of synchronous orbit, 2. GOES 2 and GOES 3 observations, J. Geophys. Res., 92, 2432-2446, 1987.

NAKAMURA, R. and T. OguTI, Drifts of auroral structures and magnetospheric electric fields, J. Geophys. Res., 92, 11241-11247, 1987.

NishitANi, N. and T. OGUTI, Auroral activity and corresponding magnetic signatures at synchronous orbit, J. Geomag. Geoelectr., 40, 423-445, 1988.

OGUTI, T., Metamorphoses of aurora, Mem. Nat'l Inst. Polar Res., Ser. A, No. 12, 1-101, 1975.

OGUTI, T., TV observations of auroral arcs, in Physics of Auroral Arc Formation, edited by S.-I. Akasofu and J. R. Kan, Geophys. Monograph Ser. 25, pp. 31-41, A.G.U., 1981.

Oguti, T. and K. HAYASHI, Multiple correlation between auroral and magnetic pulsations, 2. Determination of electric currents and electric fields around a pulsating auroral patch, J. Geophys. Res., 89, 7467-7481, 1984.

Oguti, T., T. KitAmura, and T. WATANABe, Global aurora dynamics campaign, 1985-1986, J. Geomag. Geoelectr., this issue, 485-504, 1988.

Tsyganenko, N. A. and A. V. Usmanov, Determination of the magnetospheric current system parameters and development of geomagnetic field models based on data from IMP and HEOS satellites, Planet. Space Sci., 30, 985-998, 1982. 
WiEns, R. G. and G. Rostoker, Characteristics of the development of the westward electrojet during the expansive phase of magnetospheric substorms, J. Geophys. Res., 80, 2109-2128, 1975.

Yamamoto, T., K. Hayashi, S. Kokubun, T. Oguti, T. Ogawa, N. Iwagami, T. Kitamura, O. Saka, T. Araki, K. Makita, N. Sato, T. Watanabe, R. E. Horita, and J. S. Kim, Auroral activities and long-period geomagnetic pulsations: 1 . Pc5 pulsations and concurrent auroras in the dawn sector, $J$. Geomag. Geoelectr., this issue, 553-569, 1988a.

Yamamoto, T., K. Hayashi, S. Kokubun, T. Oguti, T. Ogawa, N. Iwagami, T. Kitamura, O. Saka, T. Araki, K. Makita, T. Watanabe, R. E. Horita, and J. S. KIM, Auroral activities and long-period geomagnetic pulsations: 2 . Ps5 pulsations following auroral breakup in the premidnight hours, $J$. Geomag. Geoelectr., this issue, 571-582, 1988 b.

Yasuhara, F., Y. KAMIDE, and J. M. Holt, Field-aligned currents in high latitudes estimated from Millstone Hill radar observations of ion drifts, J. Geophys. Res., 87, 2553-2557, 1982. 